\title{
La question macédonienne pendant la guerre civile grecque
}

\section{Christina Alexopoulos}

\section{OpenEdition}

1 Journals

Édition électronique

URL : https://journals.openedition.org/ceb/2185

DOI : $10.4000 /$ ceb.2185

ISSN : 2261-4184

Éditeur

INALCO

\section{Édition imprimée}

Date de publication : 30 mars 2011

ISBN : 978-2-85831-189-7

ISSN : 0290-7402

\section{Référence électronique}

Christina Alexopoulos, "La question macédonienne pendant la guerre civile grecque », Cahiers balkaniques [En ligne], 38-39 | 2011, mis en ligne le 27 mai 2012, consulté le 06 juillet 2021. URL http://journals.openedition.org/ceb/2185 ; DOl : https://doi.org/10.4000/ceb.2185

Ce document a été généré automatiquement le 6 juillet 2021.

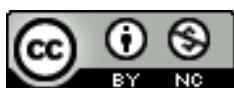

Cahiers balkaniques est mis à disposition selon les termes de la Licence Creative Commons Attribution - Pas d'Utilisation Commerciale 4.0 International. 


\title{
La question macédonienne pendant la guerre civile grecque
}

\author{
Christina Alexopoulos
}

\section{Quelques remarques préliminaires}

«Ne nous y trompons pas: l'image que nous avons de nous-mêmes et celle que nous nous faisons des autres peuples de la Terre est étroitement associée à l'histoire qu'on nous a racontée quand nous étions enfants. Elle nous marque ainsi pour l'existence entière. " (Marc Ferro) ${ }^{1}$

1 La guerre civile grecque a fait l'objet de multiples interprétations dans l'historiographie grecque et macédonienne. Dans une certaine historiographie nationaliste de part et d'autre des frontières, elle a été présentée comme une tentative des communistes grecs d'accéder au pouvoir ${ }^{2}$ et en même temps comme une tentative des Slavophones (« traitres bulgares » pour les uns et «frères esclaves » pour les autres), d'obtenir un État indépendant ou des droits minoritaires au sein de la Grèce. Certains historiens macédoniens, proches du parti VMRO-DPMNE ${ }^{3}$, qui, en général, évoquent assez peu la portée communiste de la résistance yougoslave pendant la seconde guerre mondiale en évoquant le caractère "nationaliste " de l'engagement macédonien ${ }^{4}$, interprètent le conflit grec comme une guerre qui aurait essentiellement opposé des Macédoniens et des Grecs. Si une partie de l'historiographie macédonienne appréhende la guerre civile grecque essentiellement comme une étape importante dans la construction identitaire de la nation macédonienne, à l'image des révoltes d'Ilinden ${ }^{5}$ de 1903, l'historiographie grecque a longtemps utilisé dans sa propagande la participation des Macédoniens slavophones de Grèce dans la guerre civile, d'abord en les présentant comme des ennemis intérieurs assimilables à une menace extérieure, puis en passant sous silence leur nombre et leur identité, moins dans une logique d'apaisement des relations avec la Yougoslavie voisine après la fin du conflit que dans une tentative de négation de la présence réelle sur le territoire grec de ces populations de langue et de culture slavomacédoniennes. Enfin, une nouvelle historiographie grecque de droite s'est attachée à 
montrer que le déclenchement et le déroulement de la guerre civile grecque auraient été conditionnés voire motivés par la question macédonienne ${ }^{6}$.

2 Or, malgré l'engagement d'un grand nombre de Macédoniens Slavophones de Grèce dans les rangs de l'Armée Démocratique et malgré la propagande du gouvernement grec qui a longtemps présenté les communistes comme des " éléments étrangers " ${ }^{7}$, la guerre civile grecque reste un conflit entre ressortissants d'un même pays, une guerre à fort coefficient idéologique, ayant opposé les forces communistes, issues de la Résistance, aux forces royalistes ${ }^{8}$ aidées par leurs alliés d'abord britanniques puis américains. D'un autre côté, même si les Macédoniens slavophones de Grèce impliqués dans le conflit, étaient bel et bien des habitants du pays, des " locaux ou autochtones »", comme le dit si bien le terme grec de «vтórıo » par lequel on les désignait, la guerre civile grecque a certainement revêtu une dimension internationale, dépassant les considérations de simple politique intérieure.

3 Premier conflit armé de la guerre froide, la guerre civile grecque (1946-1949) ${ }^{10}$ se place ainsi, tout comme la fondation ${ }^{11}$ de la République de Macédoine, intervenue le 2 août 1944, dans un contexte géopolitique qui transcende et, en même temps, met en jeu les frontières nationales; un cadre international défini par le rapport des forces entre Churchill et Staline, avec une répartition du monde en zones d'influence prédéterminées. Cette guerre, tout comme la lutte des Macédoniens Slavophones après la Seconde Guerre mondiale pour obtenir un État, s'inscrit dans la logique de confrontation de la guerre froide. Les communistes grecs et les combattants macédoniens doivent composer avec ses contraintes et ses schémas idéologiques.

4 Comment dans ce contexte, le Parti communiste grec se situe face aux revendications macédoniennes et à la politique de Tito? Quel est l'engagement des Macédoniens slavophones de Grèce dans la guerre civile ? Comment le discours officiel de l'État grec et l'historiographie nationale qui en découle utilisent dans leur propagande «la menace slave» et l'accusation de «trahison nationale» pour discréditer leurs opposants?

\section{Discours communiste et engagement des Macédoniens de Grèce dans la guerre civile.}

5 Il sera question de l'implication des Macédoniens à la résistance communiste et à la guerre civile grecque à travers trois axes qui forment autant d'étapes historiques: l'ambivalence des rapports entre l'EAM et le SNOF; la situation et les aspirations des Macédoniens pendant la période de la Terreur blanche; les relations entre le NOF, l'Armée Démocratique et le Parti communiste pendant les dernières phases du conflit.

\section{Les rapports entre l'EAM et le SNOF pendant l'Occupation}

6 Le Parti communiste grec, en adoptant la politique de l'Internationale Communiste, a affirmé son soutien à une "Macédoine unie et indépendante ${ }^{12}$ et partagé les revendications des communautés slavophones de Grèce dès les années trente ${ }^{13}$, même si en 1935, il a dû abandonner toute position séparatiste au profit de la proclamation du « respect des droits des minorités et l'égalité de fait avec la population grecque ». Précisons que malgré des engagements internationaux ${ }^{14}$, l'État grec avait 
systématiquement refusé de reconnaître la langue et la culture de la communauté slavophone, devenue minoritaire dans la région ${ }^{15}$ après les échanges de populations et l'arrivée massive de réfugiés hellénophones.

Les populations macédoniennes de Grèce durement opprimées par la dictature de Métaxas ${ }^{16}$ mais aussi par les régimes peu démocratiques de ses prédécesseurs ${ }^{17}$, ont vu dans l'EAM, le Front de Libération Nationale à dominante communiste ${ }^{18}$, une alternative identitaire plausible à la domination bulgare ${ }^{19}$. Pendant l'occupation nazie la population slavophone a en effet été courtisée par le Cercle bulgare ${ }^{20}$, qui a fonctionné à partir de mai 1941 comme un centre de propagande basé à Salonique, mais aussi par les résistants yougoslaves de Tempo et par les communistes grecs ${ }^{21}$ qui s'étaient prononcés contre toute modification des frontières nationales mais qui militaient dans un front antifasciste très large contre toute forme d'oppression des minorités. Finalement, deux bataillons purement macédoniens se sont formés à Florina et à Almopia. Le SNOF, un mouvement de résistance macédonienne ${ }^{22}$, proche à la fois de l'EAM et de la résistance titiste a vu le jour en octobre 1943 dans la région de Florina, un mois après l'armistice italien du 8 septembre 1943. Dans l'assemblée du Haut Commandement ${ }^{23}$ qui a été créé ${ }^{24}$, il a été question du peuple macédonien "prêt à se battre pour son droit à l'autodétermination, fraternel avec les autres peuples des Balkans, et libre d'espérer sa réunification ».

Dès le départ, le SNOF et plus particulièrement son secteur de Kastoria s'est positionné pour l'autodétermination des Macédoniens Slavophones et la reconnaissance de leur identité nationale au-delà du cadre grec. Ses revendications, soutenues par Tito ${ }^{25}$, lui ont valu la méfiance du Parti Communiste grec. Engagé au projet patriotique de l'EAM, le PCG avait explicitement renoncé à l'autonomie de la Macédoine; une thèse qui lui avait auparavant coûté très cher, puisque l'ensemble des partis traditionnels avaient saisi l'occasion pour dénoncer ses prétendues velléités séparatistes ${ }^{26}$. En mai 1944, le Bureau macédonien du Parti communiste grec a décidé la dissolution du $\mathrm{SNOF}^{27}$ et son intégration dans l'EAM, ce qui n'a pas manqué de provoquer l'indignation d'une soixantaine de Slavophones qui se sont réfugiés en Macédoine yougoslave. Après l'intervention de Tito et la médiation des Haralambidis et Tzimas, le PCG a permis le retour de ces Macédoniens et la création de bataillons macédoniens exclusivement composés de slavophones. Globalement, les relations entre les Macédoniens slavophones du SNOF et le PCG ont été tendues, envenimées d'une méfiance réciproque, toujours au sujet d'une éventuelle autonomie de la partie grecque de la Macédoine et du rattachement de celle-ci à la République yougoslave voisine.

Or, indépendamment de toute divergence géostratégique, pendant l'occupation (dans les zones de la Grèce libre) et à la libération, l'EAM a œuvré pour la reconnaissance des minorités et le respect des droits des habitants slavophones. Malgré d'importantes difficultés logistiques, un manque flagrant d'enseignants et un climat de réticence, de peur et de réaction, il a même entamé, le premier, une politique de scolarisation en langue macédonienne du mois d'octobre 1944 au mois de mars 1945, expérience d'ailleurs amenée à être renouvelée pendant la guerre civile ${ }^{28}$.

10 Si pendant la résistance et la première partie de la guerre civile, les Macédoniens slavophones de Grèce ont grossi les rangs des combattants communistes dans l'espoir d'une reconnaissance nationale que l'action de l'EAM et les positions antérieures du Parti Communiste grec avaient laissé présager, (l'Internationale Communiste s'étant prononcée pour une «Macédoine Unie et Indépendante dans le cadre de la 
Confédération balkanique »), la création informelle de la "République Socialiste de Macédoine " en août $1944^{29}$, après la première assemblée antifasciste de la Macédoine (ASNOM), est venue réconforter la volonté des macédoniens slavophones d'évoluer dans une Macédoine indépendante et unifiée.

\section{La Terreur Blanche et la population macédonienne de Grèce.}

11 Il est alors intéressant de se pencher sur les aspirations et la situation de la population macédonienne à la veille de la deuxième phase de la guerre civile, alors que le concept de «loyauté nationale», un nouveau critère de discrimination, inventé par le gouvernement commence à prendre forme.

12 À la fin de la Seconde Guerre mondiale, il y a une partie de la population macédonienne, profondément marquée par l'expérience de la résistance et de l'administration de l'EAM, qui n'est pas prête à abandonner ses récentes avancées en termes de reconnaissance identitaire et de justice sociale. À côté de cette population, à la fois proche des partisans de Tito et des communistes grecs de la région, se trouve une partie de la population qui (tout comme dans le reste du pays) a collaboré avec l'occupant, en l'occurrence bulgare ${ }^{30}$. Il existe également au sein de la population macédonienne une tendance conservatrice proche de l'ancienne EMEO, qui recommande la neutralité dans le conflit grec, espère l'autonomie de la région après l'intervention anglo-américaine et passe ses revendications identitaires au second plan. Dans ce camp, se trouvent également des Macédoniens anticommunistes bien disposés à l'égard d'un gouvernement grec qui cherche à asseoir sa nouvelle autorité sur le concept (encore mal défini) de loyauté nationale, plutôt que sur la division entre hellénophones et slavophones ${ }^{31}$.

13 Cette tentative du gouvernement d'intégrer dans son giron des slavophones « loyaux à la Nation grecque ", sans attacher d'importance à la langue vernaculaire qu'ils emploient, trouve des résistances tenaces chez sa propre majorité. Dans la pratique et au moins dans un premier temps, les persécutions massives des Slavo-macédoniens se font indistinctement, ce que regrettent par ailleurs, certains penseurs de droite ${ }^{32}$ qui craignent la radicalisation des Slavo-macédoniens et leur adhésion massive aux mouvements communistes. C'est la période de la Terreur blanche ${ }^{33}$ qui après les accords de Varkiza signés en février $1945^{34}$ sévit dans toute la Grèce rurale, touchant toute personne susceptible d'avoir une relation quelconque avec le mouvement de résistance $\mathrm{EAM}^{35}$. La presse de droite ${ }^{36}$ cautionne les persécutions ${ }^{37}$ des anciens Eamites et se met à publier face à face des photos de décapitation et des déclarations de repentir en esquissant ainsi l'espace public réservé à la gauche. Elle demande une campagne de purification ethnique, conçue sur le modèle russe ou allemand ${ }^{38}$. Après l'abstention massive des Macédoniens dans les élections du 31 mars 1946, boycottées par le Parti Communiste grec, le discours anti-macédonien se généralise dans la presse nationaliste et dans la propagande gouvernementale.

L'institution d'une nouvelle ligne de démarcation dans la rhétorique gouvernementale, celle de la "loyauté nationale ${ }^{39}$ opposant les populations "loyales", "qui pensent grec » à des traîtres/bandits communistes (forcément Slaves, « un vrai Grec ne pouvant pas être communiste ») vient changer la donne et influer sur les représentations de l'altérité. Bientôt, à l'intérieur des populations de langues différentes (grecque, macédonienne, valaque, turque, etc.) il n'y aura que des Grecs et des Bulgares et cette 
division hautement idéologique ne reposera sur aucun critère linguistique ou culturel. Elle se fera uniquement sur critères politiques indépendamment de la communauté d'appartenance des personnes concernées et entraînera la persécution de tous ceux qui seront catalogués comme Slaves. Ceux des Macédoniens qui «se repentiront » de leur participation à la résistance et s'engageront du côté gouvernemental ou dans les

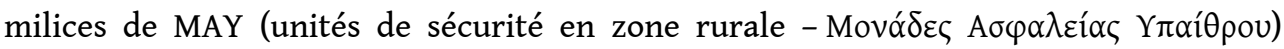
seront considérés comme "Grecs ». Ce sera le cas de toute une partie de la population macédonienne, qui souhaite rester en Grèce et qui vivra dans l'autocensure la plus totale, et dans le déni de sa langue et de sa culture ${ }^{40}$. Les autres subiront de multiples formes d'exclusion.

15 Ils seront nombreux à intégrer le NOF (Front Populaire de Libération -- НАРОДНОослОБОдИТЕЛЕН ФРОнТ) que des combattants macédoniens de Grèce ont formé le 23 avril 1945 à Skopje, sur les conseils du Parti communiste de la République de Macédoine, l'organisation des femmes AFG (Front antifasciste des Femmes -АНТИФАШИСТИЧКИ ФРОНТ НА ЖЕНИТЕ -- АФЖ) et l'union de la jeunesse NOMC (Union Populaire des Jeunes pour la Libération -- НАРОДНО-ОСЛОБОДИТЕЛЕН МЛАДИНСКИ сојуз -- номс $)^{41}$. Nous les retrouverons dans les rangs de l'Armée Démocratique, pendant toute la guerre civile. Selon des estimations officielles du NOF, ils seront 5350 en mars 1947, 11000 dont 1000 femmes en 1948 et, les derniers mois de la guerre au printemps et en été 1949, plus de 14000.

\section{L'engagement macédonien dans "le deuxième maquis " ${ }^{42}$ et l'évolution du discours communiste.}

16 Le discours du Parti communiste grec a beaucoup changé au gré des circonstances géopolitiques, pris entre les impératifs de l'Internationale Communiste, l'évolution de la guerre civile sur le terrain et le repositionnement de la Yougoslavie dans la guerre froide après la rupture entre Staline et Tito.

17 Après avoir abandonné dans les années 30, la revendication d'un statut d'autonomie pour une "Macédoine des peuples des Balkans », le Parti communiste grec a prôné le respect de toutes les minorités de la Grèce. En juin 1944, Andréas Tzimas, ancien député et cadre important du PCG, évoque avec le chef de la mission militaire soviétique au quartier général de Tito, la sensibilité du peuple grec aux questions nationales dans des termes très éloquents ${ }^{43}$. Lors du VII ${ }^{e}$ congrès du Parti communiste grec en octobre 1945, les communistes grecs ne parlent pas d'indépendance ou de réunification des trois parties de la Macédoine mais de respect de la minorité slave et d'intégrité du territoire national: «Nous déclarons qu'une coexistence pacifique avec la République yougoslave, c'est le respect absolu des droits de la minorité slavo-macédonnienne et la garantie pour cette minorité, d'un régime de pleine égalité de droits raciaux, religieux et linguistiques. C'est le seul moyen d'éviter les conflits, les incompréhensions et les controverses sur la Macédoine grecque, qui est habitée à $90 \%$ par des Grecs, ce qui la rend indissociable du territoire hellénique..$^{44}$ "

Après l'incorporation de la Macédoine du Sud dans le Royaume hellénique, «la Macédoine grecque se transforme d'une province ottomane multilingue, multiconfessionnelle et multinationale, où l'élément grec et "grécisant » se trouve en minorité face aux "éléments étrangers", en une province grecque typique, avec des minorités ethniques qui ne dépassent pas officiellement $11,2 \%$ de la population locale ; 
transformation radicale, effectuée par des vagues successives d'épuration ethnique et, surtout par l'échange réciproque, à grande échelle et obligatoire des minorités nationales entre la Grèce, la Turquie et la Bulgarie entre 1919 et $1926^{45}$. Après l'achèvement de l'échange, l'objectif le plus important que l'appareil étatique et les forces nationalistes de l'époque se fixent, est l'assimilation des minorités restées dans la région- des Chrétiens slavophones surtout, évalués officiellement à 80.000 personnes et secrètement entre 160.000 et $200.000^{46}$. La campagne assimilatrice déclenchée prend alors deux formes: s'adonner à la répression et assimilation linguistiques d'une part, visant à éradiquer le patois slave et imposer l'usage exclusif du grec ; inculquer les conceptions fondamentales du nationalisme grec dans la conscience collective des «Grecs slavophones » de l'autre part ${ }^{47}$."

19 Ce discours est progressivement modifié dès la fin de 1945. Le 28 décembre 1945, dans le plénum de l'organisation communiste de Macédoine et de Thrace, Zachariadis qualifie le NOF d'organisation antifasciste et démocratique, puis au mois de février lors du deuxième plénum du Comité central, est proclamée l'égalité des droits pour les Macédoniens de Grèce et les Grecs. Des Macédoniens intègrent en grand nombre l'Armée Démocratique et au fur et à mesure que les forces communistes se font repousser vers le nord de la Grèce, leur proportion augmente considérablement. Pour le PCG, les Macédoniens représentent un vivier de forces vives indispensables à la poursuite de la guerre. D'un autre côté, le gouvernement démocratique de la Grèce libre, proclamé le 23 décembre 1947, mène une politique de respect et de valorisation de la population macédonienne dans la continuité des pratiques inaugurées par l'EAM ${ }^{48}$ et bénéficie toujours d'un large soutien populaire dans ces régions du Nord de la Grèce.

Après le départ de Tito du Kominform en $1948^{49}$, le PCG renoue avec ses positions des années 1920 et évoque lors du cinquième plénum du Parti en janvier 1949, l'indépendance d'une Macédoine unifiée dans le cadre d'une fédération balkanique, dans l'espoir de garder les troupes macédoniennes qui pourraient être tentées par un départ chez Tito. Cette décision du cinquième plénum du Parti communiste grec dont Zachariadis lui-même explique l'importance stratégique en pleine guerre civile, sera considérée comme erronée dès l'année suivante lors du septième plénum du Parti. Entre-temps, de très nombreux communistes Grecs, des résistants de l'EAM qui avaient lutté pour leur idéal de liberté et de justice ont été condamnés à mort, inculpés de haute trahison. ${ }^{50}$

21 Quoi qu'il en soit, les thèses du Parti communiste grec et du Narodno Osloboditelniot Front ont bien connu une brève période de convergence du mois d'octobre 1946 au mois de mars $1949^{51}$, même si l'engagement des Macédoniens Slavophones avait associé aux revendications sociales du Parti communiste des aspirations sinon nationales ou ethniques au moins de reconnaissance des droits minoritaires.

Après la défaite des communistes, la situation des vaincus ne peut être décrite qu'en termes d'exclusion et/ou de persécution. Exclusion des communistes grecs du paysage politique du pays jusqu'à la chute des colonels en 1974 ; bannissement jusqu'à encore récemment des Macédoniens ${ }^{52}$ qui se voient obligés de quitter massivement leur région sans possibilités de retour, contraints par la violence (réelle et symbolique) des vainqueurs. Exil enfin des enfants (grecs ou macédoniens) qui doivent quitter leur pays natal et leur famille pour se réfugier de l'autre côté de la frontière ${ }^{53}$ et qui, dans le cas contraire, sont arrachés ${ }^{54}$ à leurs parents (jugés mauvais patriotes) et envoyés de force dans les orphelinats de la reine de Grèce, Frédérica. 


\section{trois thématiques ; « la grandeur éternelle de la Race-Nation », « la guerre sainte menée} depuis toujours par l'orthodoxie contre les Infidèles» et "la lutte contre le fléau communiste ", perçu à la fois comme " un phénomène de banditisme » à éliminer, « un péché capital » dont il faudrait se repentir et « un virus mortel », dont il faudrait être

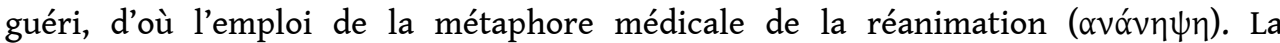
déclaration de loyauté matérialise cette idéologie de la discrimination et fonctionne comme une déclaration de repentir généralisée.

dant et après la guerre civile, l'idéologie dominante a utilisé le concept de « loyauté nationale " pour anéantir toute perspective de changement et pour rompre avec les pratiques de démocratisation du pays inaugurées par l'expérience de la Résistance. Elle a puisé dans l'idéologie anticommuniste de Métaxas les éléments qui ont permis de donner une matière sémantique à «la loyauté nationale", comme concept transcendant les divisions politiques anciennes. La rhétorique sur «la loyauté nationale » s'est avérée être une construction tardive ${ }^{58}$, créée de toutes pièces et, pour ainsi dire, dans l'urgence, dans le but de contrer « la menace communiste ». En absence d'autres référents idéologiques, l'anticommunisme est devenu l'élément fédérateur qui a réuni autour de lui, les Venizélistes et les Royalistes, les Libéraux et les Populistes, les alliés des Allemands et ceux des Anglais et qui a supprimé toutes les divisions précédentes ${ }^{59}$. L'idéologie anticommuniste de "la loyauté nationale » s'est édifiée en système de pensée appelé à interpréter l'expérience de la guerre civile et la question macédonienne. La vision du monde qui en a découlé et qui a présidé à la perception du 
conflit et à l'appréhension de la différence (idéologique ou ethnique) de l'adversaire, s'est exprimée dans un discours stéréotypé substituant à la fonction symbolique du langage, l'imaginaire d'un conflit et d'un ennemi dépossédés de leurs noms ${ }^{60}$.

La thèse des vainqueurs, considérée par la droite traditionnelle, comme le seul cadre interprétatif historiquement acceptable ou possible, sera celle de la manipulation de la masse des combattants / résistants par la direction procommuniste du mouvement de résistance EAM/ELAS et de son successeur, l'Armée Démocratique ${ }^{61}$. Le discours gouvernemental, infantilisant et paternaliste, introduit la notion de " pur Grec » abusé par les « ennemis de la Nation » et oppose dans une série de signifiants très instructive les «fils indignes de la Patrie » voire les «traitres vendus aux Slaves » aux vaillants descendants des héros de l'Antiquité ou de la guerre d'Indépendance de $1821^{62}$. Il y aurait donc un "bon peuple loyal », certes, quelque peu naïf, qui aurait été berné par les promesses, forcément mensongères, d'une élite communiste composée de mauvais Grecs, voire même de non-Grecs, cette déchéance symbolique étant bien traduite par le vocable d'EAM-o-bulgares ${ }^{63}$. Comme le fait remarquer Stratis Bournazos ${ }^{64}$, l'ennemi intérieur est systématiquement assimilé à un danger extérieur et on ne se réfère aux communistes que par des périphrases ou des mots composés, comportant les termes « slave » et « bandit » : slavo-communistes, esclaves des Slaves, bandits de communistes ou encore mercenaires communistes, la liste des qualificatifs est longue...

La propagande officielle s'obstine à parler d'incidents de banditisme conjoints à une agression étrangère et refuse de parler d'une guerre civile. Dans un discours où la moitié des habitants du pays deviennent d'un jour à l'autre des «traîtres bulgares », la réalité d'une guerre fratricide est occultée et le conflit armé se travestit en lutte contre le banditisme. Nikos Sidéris ${ }^{65}$ dans son article sur la psychologie politique et la culture de la guerre civile qualifie ce renversement du sens des signifiants de « meurtre du sens propre» ou mieux de «déni du sens figuré ». Et il spécifie que l'intériorisation psychologique de l'expérience de la persécution s'est produite dans le refus d'un savoir, voire l'exclusion des référents symboliques indispensables au respect de la dimension métaphorique du langage, notamment à travers le déni des signifiants tel que " opposant politique " ou "guerre civile ", ce paradoxe entraînant immanquablement la dépersonnalisation de l'adversaire, l'anéantissement de l'individu et l'annihilation du réel. Nous pourrions même ajouter que le discours sur la menace communiste emprunte les traits d'une vraie «novlangue $»^{66}$, constituée d'affirmations qui s'autoexcluent.

La phraséologie de la déclaration de repentir évoque la propagande habituelle du discours gouvernemental qui opère à la fois une réappropriation idéologique de l'héritage historique de la région (antique ou byzantin) et une falsification du passé récent des résistants. La pression morale et la torture physique pratiquées sur les détenus pour leur faire signer la déclaration de repentir sont ainsi accompagnées de cours de « rééducation civique » où l'on cherche à déconstruire l'identité des détenus et à leur imposer un modèle factice du bon Grec, qui serait pétri des enseignements de la civilisation antique et de la religion orthodoxe ${ }^{67}$. Les opposants à la monarchie et à la coalition anglo-américaine seront tour à tour privés de leur identité nationale, de leur statut de prisonniers politiques et de leur passé de résistants dans la mesure où la propagande officielle tient à ce que la guerre civile appelée "lutte contre le banditisme » résulte des agissements de groupes de criminels, assujettis aux Slaves et 
nie aux Résistants communistes (Grecs ou Macédoniens) leur passé de partisans, voire de bons patriotes.

31 Présenter la guerre civile grecque comme une guerre de plus contre des envahisseurs slaves, venus du nord, permet de minimiser l'importance numérique des partisans de l'Armée Démocratique (Grecs ou Macédoniens habitant la Grèce et en aucun cas membres d'une brigade internationale) et inscrit le présent conflit armé dans le "glorieux passé du pays ». Le discours officiel établit de nombreux parallélismes avec les guerres menées dans le passé et projette ce conflit dans un continuum historique qui partirait de la haute antiquité pour arriver à l'épopée albanaise de 1941 en passant par la guerre d'indépendance de $1821^{68}$. Les Slaves du X $\mathrm{X}^{\mathrm{e}}$ siècle et ceux des années 1940 sont présentés comme les sempiternels ennemis du pays contre lesquels les Grecs se seraient toujours victorieusement battus.

L'identité de l'adversaire se construit dans le déni de la dimension idéologique du conflit. L'idéologie communiste et les aspirations sociales ou communautaires de l'adversaire grec ou macédonien passent presque pour une conséquence naturelle d'une différence raciale et nationale. Dans le discours de la déclaration de repentir et de la presse progouvernementale, les Slaves sont considérés "comme des êtres inférieurs, des peuples sauvages ", qui ne pourraient qu'adhérer au communisme. C'est un discours manichéen qui vient opposer les «Grecs civilisés » imprégnés de valeurs «nationales » aux ennemis de toujours, les « Slaves", tous les communistes grecs étant assimilés à des ennemis extérieurs. Par opposition à « ces ennemis étrangers ou à la solde des étrangers ", les vrais Grecs, seraient porteurs de valeurs supérieures et leurs combats aboutiraient forcément à une "nouvelle » victoire. Dans la phraséologie qui se dégage des déclarations de repentir et des discours gouvernementaux, l'anticommunisme et le nationalisme grecs seraient alors la lutte éternelle des civilisés contre les barbares ou encore des Chrétiens contre les infidèles.

La déclaration de repentir emprunte au discours religieux les métaphores verbales et les pratiques de la repentance. La mortification de la chair conditionne la purification de l'âme, le déni de l'altérité et le dénuement des signifiants de leurs sens sont préalables à l'expiation du signataire, et d'ailleurs s'accommodent assez bien du discours rédempteur de l'Église grecque ${ }^{69}$. Après les purges de l'Église grecque, l'adhésion au communisme est communément présentée comme un péché dont il faut se repentir. Le discours de l'église et des organisations religieuses, tout comme celui de la propagande gouvernementale cherchent à faire peur et à déshumaniser l'adversaire idéologique. Stratis Bournazos démontre comment toute critique du socialisme réel est délaissée au profit d'une présentation fantastique ou irréaliste du «monstre communiste $»^{70}$. Maria Siganou ${ }^{71}$, dans son article sur les composantes idéologiques du discours religieux pendant la guerre civile cite l'exemple de l'organisation Zoi, organisation parareligieuse assurant l'expression de l'anticommunisme orthodoxe, qui diabolise le communisme au point d'en faire une expression suprême de mal absolu ${ }^{72}$.

Le même discours de terreur qui rejette l'altérité au point de l'assimiler à une maladie se retrouve dans les métaphores médicales. Très présentes dans les déclarations de repentir, ces métaphores seront appelées à être réutilisées vingt ans plus tard par la dictature des colonels.

Dans le contexte de la guerre civile, les prisonniers doivent choisir entre le rejet de leur action politique et /ou militaire contre l'occupant nazi, les milices collaborationnistes et l'armée gouvernementale, et la persévérance dans leur " erreur idéologique ». S'ils 
refusent de se débarrasser, pour reprendre la terminologie médicale de l'époque, du " virus » ou de « la maladie mentale » du communisme et s'obstinent à ne pas signer de déclaration, ils sont exposés à subir tout le processus de rééducation, lequel vise encore et toujours, à diviser les prisonniers en deux catégories : ceux qui (indépendamment de leur origine ethnique et de leur engagement idéologique) avoueront leurs fautes et pourront se racheter en faisant une croix sur leur identité antérieure mais aussi en participant activement à la dénonciation ou à la rééducation ${ }^{73}$ de leurs anciens camarades et en faisant le jeu de la propagande gouvernementale et ceux qui refuseront de se repentir et qui se retrouveront bannis de la société, niés dans leur existence physique et morale, condamnés à la déportation, la prison ou l'exil.

La déclaration de repentir n'est qu'une première étape dans la reconversion idéologique, une concession qui sera appelée à être suivie par d'autres. Elle s'inscrit dans un mécanisme de déconstruction aussi bien de la personnalité des signataires que du lien social à l'intérieur de la communauté des prisonniers politiques. La déclaration agit comme un facteur de division qui vient briser la cohésion et la solidarité de la collectivité. Elle sert aussi d'alibi à un certain discours communiste qui évite de reconnaître les erreurs stratégiques du Parti et attribue la défaite de la guerre civile aux « traitres » et autres " apostats " ${ }^{74}$. Dans une société balkanique, qui au-delà de ses divisions, sacralise la "parole donnée " et fonctionne selon un code de l'honneur ${ }^{75}$ rigide, le mépris devient alors le lot des renégats qui ne trouvent grâce ni auprès de leurs anciens camarades ni auprès des nationalistes.

Solution individuelle présupposant la rupture du lien avec la communauté des pairs, la signature de la déclaration aboutit ainsi à la double exclusion du signataire, tant par l'ensemble des camarades à qui le Parti communiste interdit de signer que par les pouvoirs publics qui demanderont au repenti de prouver constamment la véracité de sa reconversion en «bon grec » en continuant à le traiter en citoyen de seconde zone.

\section{L'exclusion de la gauche}

38 Ce discours qui vient sceller l'exclusion de la gauche du paysage politique du pays montre comment le verbal est destitué de ses fonctions pour laisser la place aux images d'une violence physique "décomplexée ». Il montre aussi la continuité des versions officielles pendant et longtemps après la guerre civile. Jusqu'à la chute de la dictature des colonels, la version des vainqueurs de la guerre civile se résume en un discours manichéen qui substitue à la critique politique d'un système, une peur archaïque, presque aussi primitive que les réponses apportées par les "pratiques de rééducation. » La joute verbale y laisse bien la place à la volonté d'extermination physique de

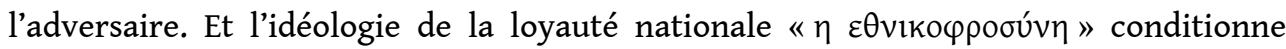
jusqu'à la caricature la vie politique et intellectuelle du pays.

Au-delà du versant idéologique, la notion de « loyauté nationale » comporte un versant juridique, voire bureaucratique qui se matérialise par la signature d'une «déclaration de loyauté ». La " déclaration de loyauté » instituée en 1948 par la loi d'urgence 516 rend encore plus visible l'exclusion de la gauche. Comme l'explique fort bien J. Dalègre, "à côté de ces mesures judiciaires, la contrainte la plus forte est la déclaration de loyauté. Ce certificat qui atteste des pensées nationales du candidat devient indispensable à toute vie normale : celui qui ne l'a pas ne peut pas travailler dans les services publics (1948), ni dans la marine marchande (1953), ni dans les Transports 
Publics (1954), il ne peut travailler ni à la DEI (électricité) ni à l'OTE (téléphone), ni au service des eaux, ni au port du Pirée, ni dans les services considérés comme d'intérêt général (les hôpitaux en 1948 et même les services d'irrigation). Il ne peut obtenir de permis de conduire (1950) ou de permis de chasse, ni entrer à l'Université (1951) ou dans une école d'ingénieurs (1954); il ne peut être reconnu comme invalide de guerre (1950), il ne peut accéder à ses terres si elles sont situées dans la zone frontalière (1951). Il ne peut même pas quitter le pays! En réalité, on le laisse franchir la frontière, car la loi permet, si on juge qu'il n'a pas l'intention de revenir, de le priver de sa nationalité et d'empêcher son retour. ${ }^{76}{ }^{\prime \prime}$

Une législation d'exception survit inchangée ${ }^{77}$ jusqu'en 1962, et légèrement transformée sous G. Papandréou, elle revient au goût du jour sous la dictature des colonels. Conçue sur le modèle du serment américain, elle sert de déclaration de repentir supplémentaire, destinée cette fois-ci à l'ensemble de la population. Il s'agit de prouver sa «loyauté » collaborationniste vis-à-vis du régime ou bien de se faire pardonner la «faute originelle » d'avoir cru dans le rêve de changement que l'EAM avait incarné. À la différence de la déclaration de repentir qui vise ceux qui s'étaient engagés physiquement ou moralement du côté de l'EAM, la "déclaration de loyauté » concerne tout le monde : parce que tout le monde est suspect d'y avoir cru, tout le monde doit vivre dans la culpabilité de ce péché originel, qui s'est transformé en acte fondateur de «la pensée nationale». L'aspect artificiel et bureaucratique de la démarche, le caractère stéréotypé d'un texte qui sonnait faux, importaient peu. Pour les vainqueurs, leur cause était juste et leur discours justificateur pouvait et devait rester inchangé.

Pour y arriver, il aura fallu procéder à une reconstruction autocensurée de la mémoire officielle et s'adonner à des pratiques juridiques et historiographiques de légitimation et / ou de déni de certains aspects du conflit. Dans leurs discours officiels sur la période 1936-1949 et dans leur propagande anticommuniste, les vainqueurs de la guerre civile ont utilisé la notion de "loyauté nationale", mélange de nationalisme orthodoxe agressif et de propagande anticommuniste pour faire accepter et / ou nier la violence à laquelle étaient soumis les opposants au régime et la minorité macédonienne, légitimer la politique ségrégationniste de l'anticommunisme d'état et construire une image de la résistance qui ne serait pas liée à celle de l'EAM, en minimisant par la même occasion son impact sur la population. La mémoire officielle de la Seconde Guerre mondiale et de la guerre civile s'est alors formée en rupture avec l'expérience de la résistance de l'EAM et dans l'autocensure des pratiques collaborationnistes des bataillons de sécurité. La question macédonienne a également été occultée et la version historiographique officielle au moins jusqu'à la chute de la dictature des colonels s'est limitée à propager la thèse de la trahison communiste face aux envahisseurs slaves. Accablée entre raison d'État et état d'urgence, la minorité macédonienne a fait l'objet d'un déni total de la part des institutions du pays et de l'historiographie officielle des vainqueurs. Les premiers signes de démocratisation n'ont été perçus par la population slavophone qu'en 1981 avec l'arrivée du parti socialiste au pouvoir. La langue locale a pu être parlée publiquement sans conséquence. Cependant, l'État grec n'a autorisé le retour qu'aux seuls réfugiés politiques "d'origine grecque ". D'ailleurs, "en introduisant un critère ethnique, cette exception discriminatoire reconnaît indirectement la réalité d'une question minoritaire en Macédoine grecque ${ }^{78}$. 


\section{Conclusion : La question macédonienne, un des derniers avatars de l'idéologie de la loyauté nationale?}

$\mathrm{Au}$ moment de conclure force est de constater que le déni dont la question macédonienne a été frappée fait appel à un autre interdit, celui qui a pesé sur la mémoire de la guerre civile.

La mémoire de la guerre civile s'est construite dans le non-dit et l'autocensure. Pendant de longues années, cet événement majeur de l'histoire récente du pays a été considéré comme un sujet tabou, frappé, pour ainsi dire, d'une loi d'omerta et n'a été abordé que de manière assez indirecte ou détournée dans les diverses tentatives historiographiques ${ }^{79}$ et / ou les discours des principaux acteurs ${ }^{80}$. Certes, après 1974 et surtout 1981 et 1989, la parole s'est progressivement libérée pour reconnaitre qu'il s'agissait bien là d'une guerre civile dont il fallait raconter l'histoire. Mais de manière assez paradoxale, la loi du silence a abouti à un "devoir d'oubli » ${ }^{81}$, au nom d'une réconciliation $^{82}$ nationale conçue sur le mode amnésiant, plus que réparateur ${ }^{83}$. La transmission problématique de la mémoire de la souffrance des vaincus a été accompagnée d'une mémoire autocensurée, bien que triomphaliste, dans l'historiographie des vainqueurs.

Pendant la dictature, l'esprit de guerre civile avait atteint son paroxysme puis, il avait progressivement commencé à reculer. Le rejet massif du régime dictatorial par la société civile dans son ensemble avait facilité le rapprochement entre des acteurs de différentes sensibilités politiques annonçant ainsi la démocratisation du pays. L' idéologie de la loyauté nationale semblait même destinée à disparaître, ultime vestige d'un terrorisme d'État qui avait longtemps su taire son nom. Le traitement de la question macédonienne par les médias et certains partis politiques grecs ${ }^{84}$ montrent qu'il n'en est rien. Ce vieux fond de nationalisme agressif, qui avait conditionné jusqu'à la caricature la vie politique du pays est toujours perceptible dans l'appréhension de la question macédonienne. Dans ce sens, le traitement de la question macédonienne reste un des derniers avatars de l'idéologie de la loyauté nationale.

L'oubli amnésiant plus qu'amnistiant manifeste dans une transmission problématique de la mémoire de la guerre civile se substitue à la réflexion critique sur l'héritage nationaliste de l'idéologie de la «loyauté nationale ». Et ce discours du déni de l'Autre, idéologiquement dominant jusqu'à la chute des colonels réapparaît violement dans le traitement de la question macédonienne. Or, comme le dit si bien Loring Danforth, que Madame Skoulariki, cite dans son article sur la crise macédonienne. « Le nationalisme, en égalisant la loyauté à l'état avec l'appartenance à la nation, transforme par définition les membres des minorités nationales en ennemies de l'État. »

\section{NOTES}

1. Les travaux de Marc Ferro ont permis de mettre en avant le rôle de l'enseignement de l'histoire dans l'édification de la mémoire collective. Cf. Marc Ferro, Comment on raconte l'histoire 
aux enfants : à travers le monde entier, Payot, coll. « Aux origines de notre temps ", Paris, 1981, Marc Ferro, L'Histoire sous surveillance: science et conscience de l'histoire, Calmann-Lévy, coll. «Intelligence de l'histoire », Paris, 1985, Marc Ferro, Que transmettre à nos enfants (avec Philippe Jammet et Danièle Guilbert), Le Seuil, Paris, 2000, Marc Ferro, Les Tabous de l'histoire, Nil, Paris, 2002. Dans Les manuels scolaires, miroirs de la nation? (de Verdelhan Bourgade/B, Michèle Verdelhan-Bourgade, Béatrice Bakhouche, Richard Étienne, Pierre Boutan, Collaborateur Collectif, publié chez L'Harmattan, Paris, 2007) les auteurs partent du constat que les livres d'école ne sont pas des objets banals et approximatifs qui s'effaceraient des mémoires adultes, pour mener une réflexion originale sur leur rôle sociétal. Un rôle qui dépasse la simple transmission de connaissances scolaires et qui fait de ces acteurs de culture des témoins privilégiés des valeurs et des pratiques sociales dans leurs variations et leurs continuités historiques et géographiques. L'étude des manuels offre alors des aperçus pertinents sur les idées, mais aussi les préjugés qu'une société véhicule. Le thème de la nation qui a été choisi par les auteurs comme principal fil conducteur, en raison de ses implications d'ordre historique, géographique, linguistique, culturel, et aussi moral et politique, se prête particulièrement bien à cet exercice de réflexion historiographique et la contribution de $\mathrm{C}$. Angélopoulos sur la Grèce y éclaire de manière originale la construction identitaire dans le discours éducatif grec. Toujours à propos de l'identité grecque dans l'enseignement secondaire, je renvoie aux travaux de Constantin Angélopoulos sur l'image de l'Autre (Cf. C. Angélopoulos, "Proclaiming greek national identity through dialectic in school textbooks of the greek secondary education between 1950-1990" in The image of the other/neighbour in the school textbooks of the balkan countries, Athènes, 2001 : Typothito - George Dardanos) et sur le traitement de la question macédonienne dans l'historiographie grecque. Cf. Éclairage sur la (Re-)naissance de la question macédonienne dans les manuels grecs d'histoire de l'enseignement secondaire (1950-1995) Coll. Grécité, Montpellier III, Montpellier, 2004.

2. L'historiographie de droite en Grèce a longtemps essayé de présenter la guerre civile grecque comme une tentative des communistes de s'emparer du pouvoir. Or, cette formulation est loin de refléter la réalité d'exclusion et de persécution dont les communistes et les anciens éamites ont été les principales victimes. Pour Philippos Iliou, le Parti Communiste et ses alliés ont beaucoup

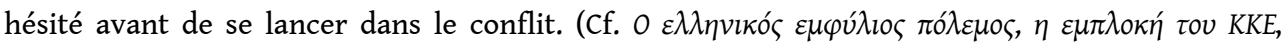

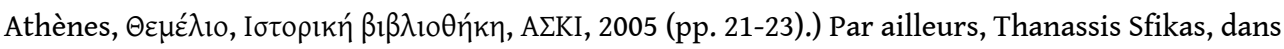
son article sur la dimension " pacifiste et guerrière » de la guerre civile grecque démontre que le Parti communiste grec avait essayé à plusieurs reprises d'éviter le déclenchement et même d'arrêter la poursuite de la guerre. On compte même 21 tentatives de résolution du conflit,

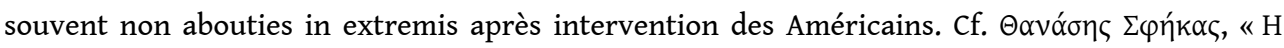

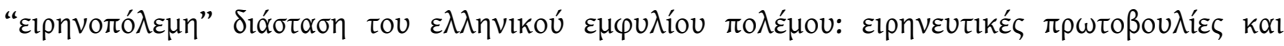

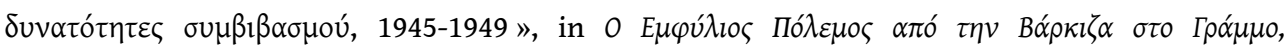

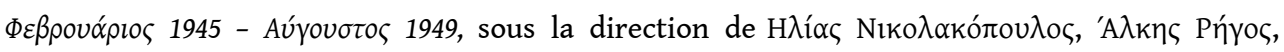

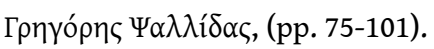

3. Après la fin du communisme, une nouvelle génération d'historiens proche de VMRO-DPNME, remet en question l'héritage yougoslave, reproche à l'ancienne génération d'historiens, proches de l'Union sociale- démocratique, des affinités proserbes et insiste sur le caractère national (et non pas social) de la résistance du peuple macédonien. Dans cette approche historiographique, on estime que les régiments slavophones de l'ELAS (et plus tard de l'Armée Démocratique) se battaient moins par conviction communiste ou dans la perspective d'une reconnaissance des droits de la communauté macédonienne au sein de l'État grec et plus pour la séparation et l'autonomie de la Macédoine. Cf. Todor Čepreganov (sous la direction de) Britanski Voeni Misii vo Makedonija 1942-1945, Skopje, éditions des Archives d'État, 2000.

4. Cf. Vera Aceva, Pismo do Tempo, Skopje, 1991. 
5. La plupart des figures emblématiques du NOF ont inscrit leur combat dans la continuité de la révolte des paysans pauvres qui s'étaient insurgés en 1903 contre l'administration ottomane à Ilinden. Les événements d'Ilinden, mémorés et commémorés ont formé un point de repère dans la construction identitaire de la Macédoine, tout comme l'expérience de la Résistance et de la guerre civile grecques. Après la défaite des communistes, vingt mille combattants macédoniens se sont réfugiés en République de Macédoine. Leur mémoire de la guerre civile grecque a ainsi participé de la construction identitaire de l'historiographie macédonienne à la manière de celle

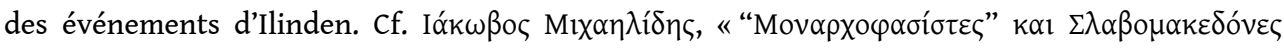

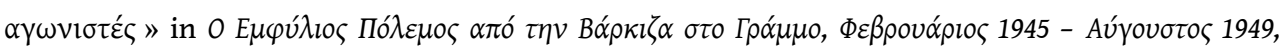

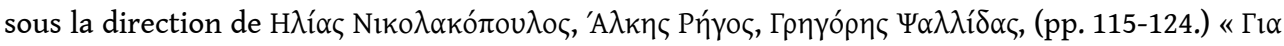

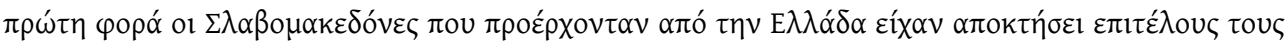

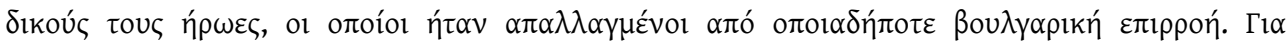

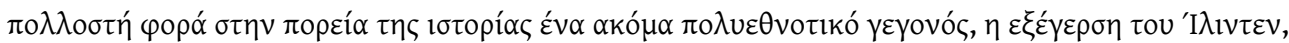

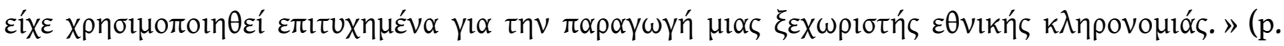
231) L'historien grec Iacovos Michailidis trouve que la guerre civile grecque constituerait un acte fondateur dans la construction idéologique de la Nation macédonienne et que les révoltes multiethniques d'Ilinden auraient été «utilisées » dans la production singulière d'un héritage

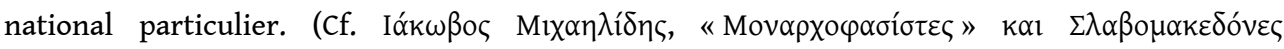

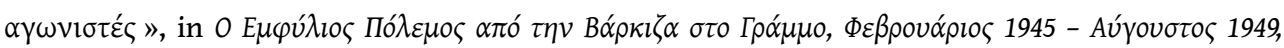

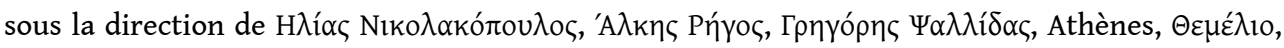
2002, pp. 222-232.) D'un autre côté, l'historiographie grecque a souvent tendance à surévaluer le caractère artificiel de la construction de l'identité nationale en Macédoine, en oubliant par la même occasion que toute construction identitaire d'un État-nation, à commencer par celle de la Grèce, se fait sur la base d'un héritage historique ou culturel, «utilisé à bon escient » par les principaux intéressés (et par définition arbitraire), puisque le concept de Nation n'est rien d'autre qu'une construction idéologique. Pour une analyse critique de cette approche essentialiste de l'identité et une réflexion très intéressante sur le droit à l'autodétermination sur la base de la volonté des citoyens et non pas sur un monopole quelconque du passé historique, cf.

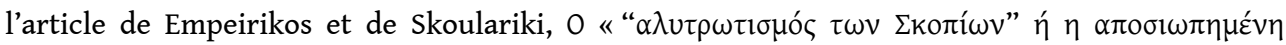

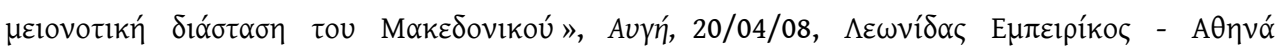

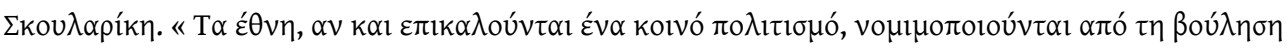

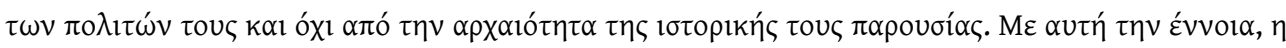

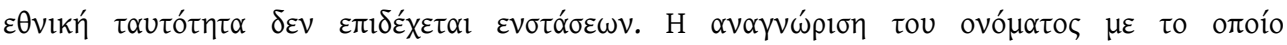

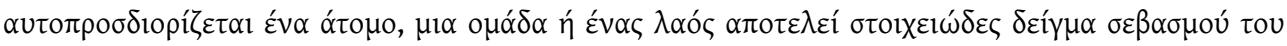

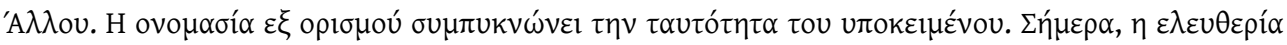

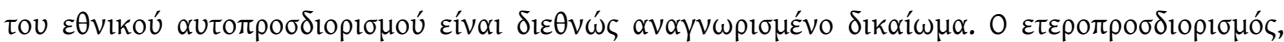

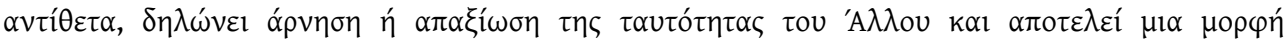

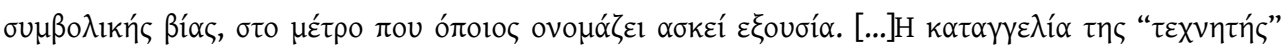

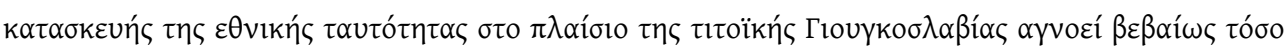

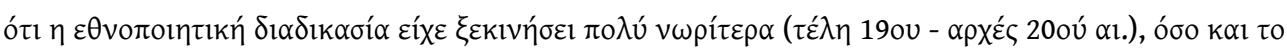

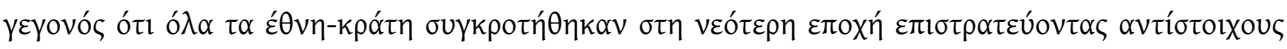

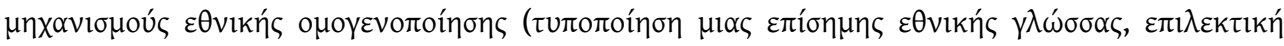

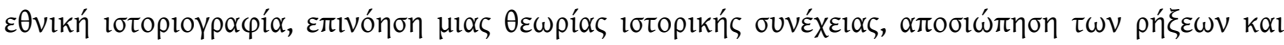

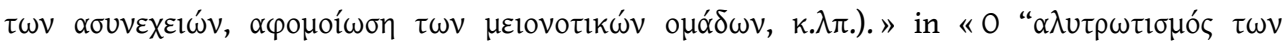

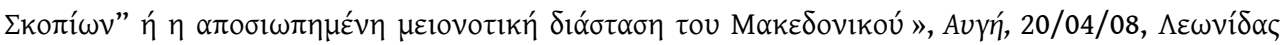

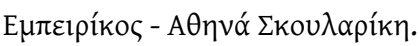

6. Tout récemment, l'historien officiel de la question en Grèce, Evangelos Kofos, a écrit que c'était la question macédonienne qui avait décidé le Parti Communiste à se lancer dans la guerre civile. 


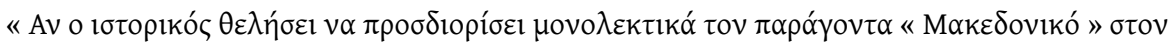

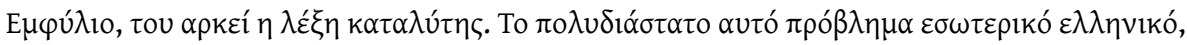

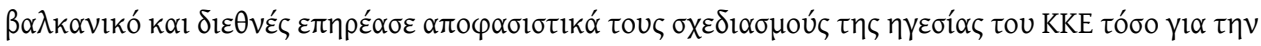

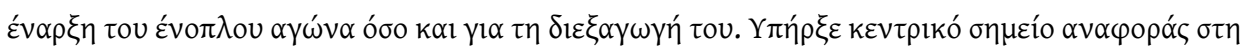

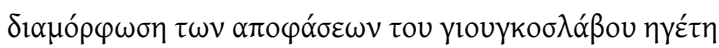
Títo

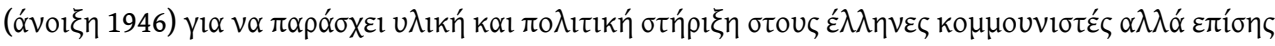

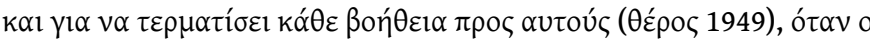

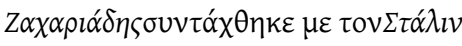

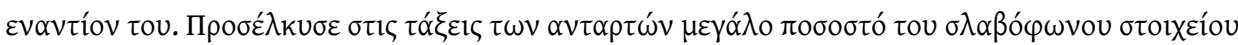

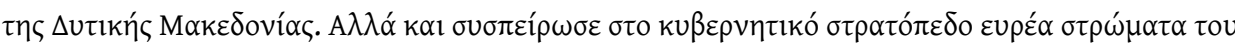

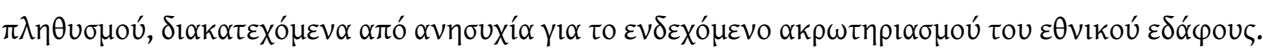

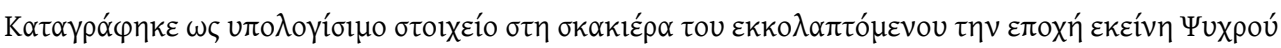

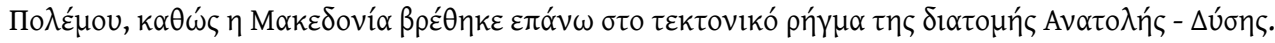

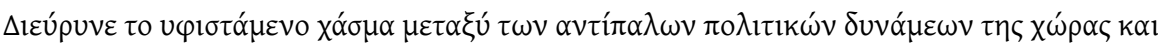

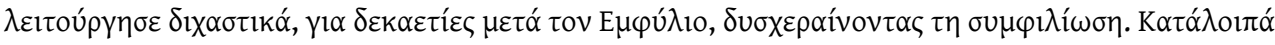

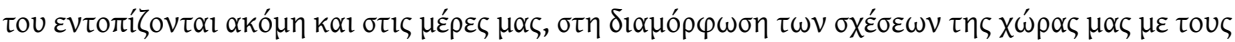

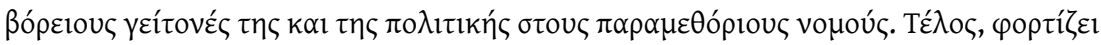

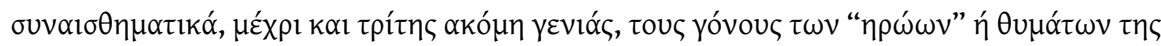

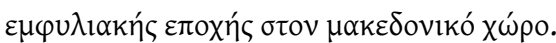

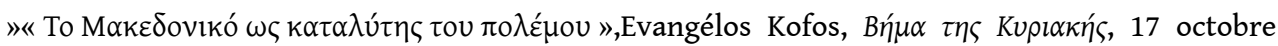
1999.

7. Le gouvernement grec dénonce à l'ONU le 3 décembre 1946 une agression étrangère; $c f$. Joëlle Dalègre, La Grèce depuis 1940, L'Harmattan, Paris 2005, p. 79.

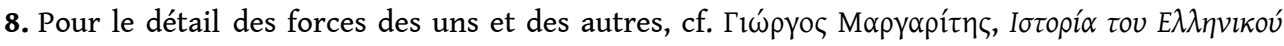

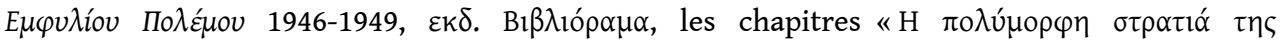

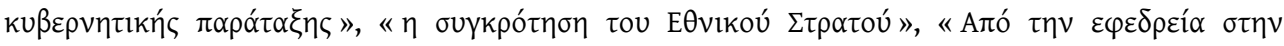

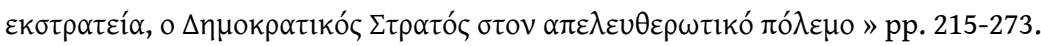

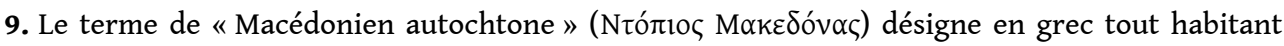
autochtone de la Macédoine grecque (Macédoine de l'Égée). Cette dénomination oppose les «Macédoniens autochtones » aux réfugiés venus d'Asie Mineure à l'entre-deux-guerres après l'échange des populations. Dans certaines parties de la Macédoine de l'Égée, les populations slavophones ont utilisé ce terme pour se différencier des Macédoniens albanophones et des

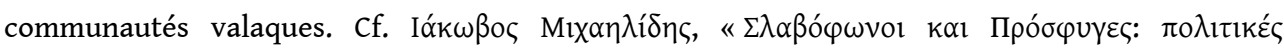

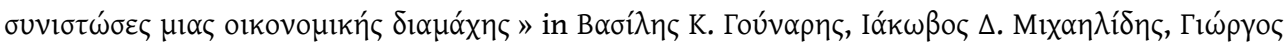

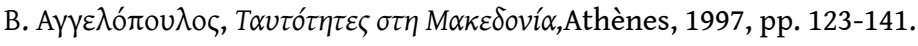

10. De nombreux historiens font remonter le début de la guerre civile, aux événements de décembre 1944 et aux conflits armés ayant opposé les différents groupes de résistants dès 1943, voire même encore plus loin, aux confrontations antérieures entre milices nationalistes et ELAS, au risque bien sûr de faire disparaître la spécificité de la période de la Résistance au profit de la seule évocation de la guerre civile grecque. Pour la période allant de la fin de la Seconde Guerre

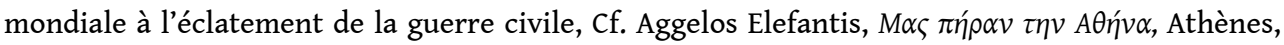

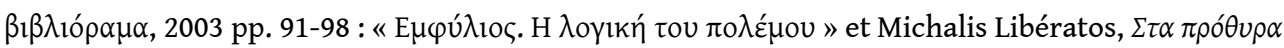

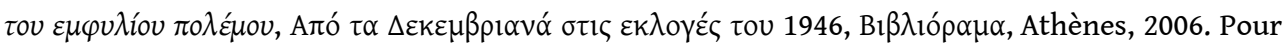
le rôle des milices nationalistes, leur collaboration avec les occupants Nazis et leurs confrontations avec les forces de l'ELAS, cf. «E

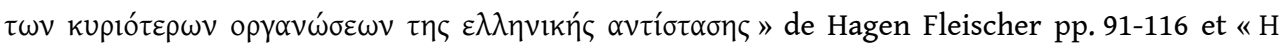

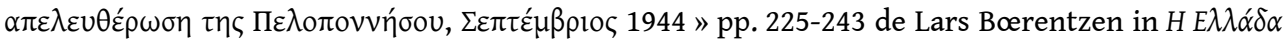

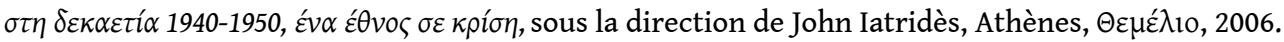


11. Sur la fondation de la République de Macédoine par l'ASNOM et une réflexion sur l'évolution de l'État-nation, Cf. E.Dimitrov, G. Caca, V. Ivanovski (sous la direction de) ASNOM:Pedeset godini makedonska država 1944-1994. Prilozi od naučen sobir održan na 17-18 Noemvri 1994, Skopje, Académie Macédonienne des Sciences et des Arts, Institut d'Histoire Nationale, 1995. Voir également, C. Grozdanov, B. Ristovki, I. Katardžiev, P. Andreevski, T. Čepreganov, (sous la direction de) Republika Makedonija 60 Godini po ASNOM: Zbornik od naučniot sobir po povod Šeesetgodišninata od ASNOM ordžan vo Skopje na 15-16 Dekemvri 2004 godina, Skopje, Académie Macédonienne des Sciences et des Arts, 2005.

12. Le troisième congrès extraordinaire du Parti communiste grec (du 26 novembre au 3 décembre 1924) a décidé (en suivant en cela la fédération communiste des Balkans) d'œuvrer pour l'indépendance de la Macédoine et de la Thrace dans le cadre d'une fédération balkanique qui respecterait «les droits du peule macédonien». Pour une présentation détaillée des discussions et des décisions prises dans ce congrès, voir l'édition du Département d'Histoire du

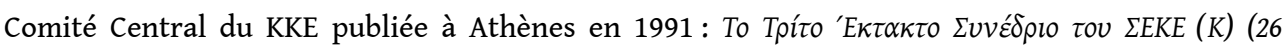

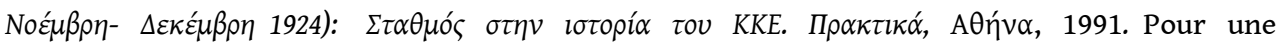
présentation des positions des différents partis communistes sur la question, voir l'étude de

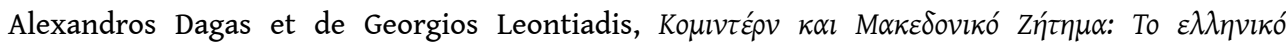
$\pi \alpha \rho \alpha \sigma \kappa \eta ́ v i o, ~ 1924$, Athènes, 1997.

13. Cf. P. Panayotopoulos, Réclusion et idéologie, une sociologie politique de la réclusion à partir de l'expérience des communistes grecs", mémoire de DEA soutenu à Paris, en septembre 1994. P. Panayotopoulos fait référence aux travaux de A. Elephantis, La promesse de la révolution impossible, Olkos, 1976, (pp. 36-38) et de I. Papathanassiou, Contribution à l'histoire du Parti Communiste Grec Thèse de Doctorat, Université Paris X, 1988, (p. 63) et note qu' "après de fortes pressions, l'Internationale Communiste arrivera en 1924 à convaincre le PCG de se positionner en faveur «de la Thrace et de la Macédoine unies et indépendantes ».Cette position explicitée -- avec maintes difficultés -- en termes d'internationalisme prolétarien et de combat anti-impérialiste dans la péninsule Balkanique, mènera à un fort isolement du parti. (Cf .H.Vlavianos, "The Greek Communist party under siege" in Veremis-Highmam, Aspects of Greece 1936-1940, Eliamep-Vryonis Center, Athènes, 1993, p. 194.) Dans le contexte provoqué par le Désastre d'Asie Mineure, elle sera retenue comme une provocation à l'égard du sentiment national et sera en tant que telle, abondamment utilisée par ses adversaires. Position qui, en 1935 sous la pression des adversaires politiques du parti, se transformera en position "sur l'égalité des droits des minorités nationales ». (Cf. Idem, p. 195.) [...] L'accusation contre le PCG qui était inscrite dans la réclusion du PCG avant les années 1940 visait à une stigmatisation d'ordre social. Pourtant, l'accusation politique « de trahison de la nation » commencera à être effective, à partir de cette décision sur la Macédoine, progressant peu à peu, tout comme son « palliatif patriotique » mis en avant par le PCG à partir de 1934. (Cf. Panayotis Noutsos, « Le discours idéologique du PCG de 1940 à 1934 » in La Grèce de 1940, Etairia Spoudon Néo-ellinikou Politismou kai genikis paidias, Athènes, 1993, (en grec), pp. 180-185.) Inversement, le discours adverse au PCG sera légitimé durant toute la période de l'Etat anticommuniste d'après la Guerre Civile, en référence à l'Affaire de Macédoine. (Cf. Les procès contre l'espionnage au printemps 1960 à Athènes, Synchroni Epochi, Athènes, 1989, pp. 90-91.) Le PCG donnera de la sorte, à partir de 1940, dans la Résistance, une réponse globale à l'accusation qui faisait de lui, un parti de «trahison nationale »; malgré cela cette accusation se confirmera justement après les années 1940, et c'est autour d'elle que se mettra en place toute l'attaque anti-communiste de l'après-guerre. » (pp. 121, 122)

14. Pour une présentation des accords de Neuilly (14-27 novembre 1919) et de Sèvres (10 août 1919) et du décalage de ces engagements de la Grèce avec la politique de répression menée sur le

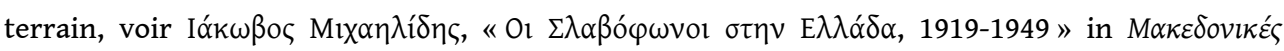

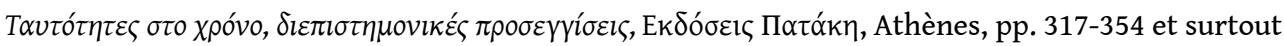

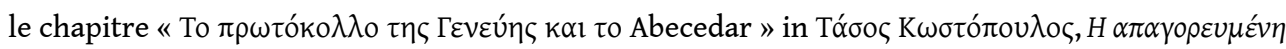




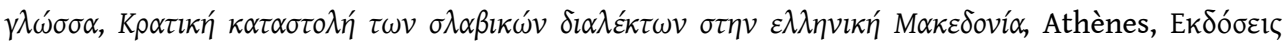

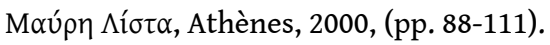

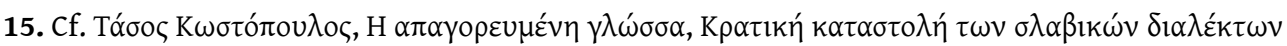

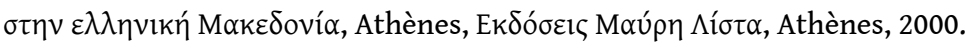

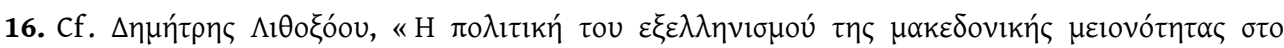

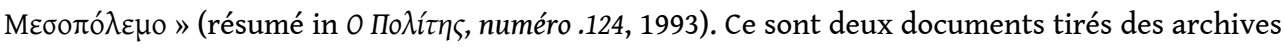
de Ioannis Métaxas, révélateurs de l'hostilité étatique face aux autochtones slavophones dans la Macédoine de Grèce.

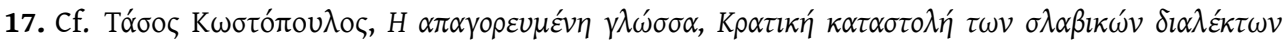

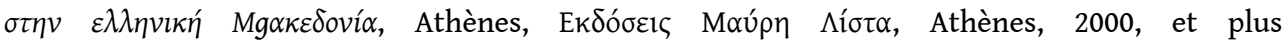

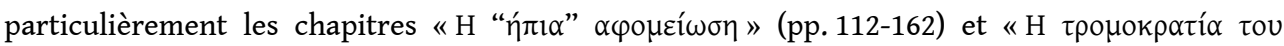

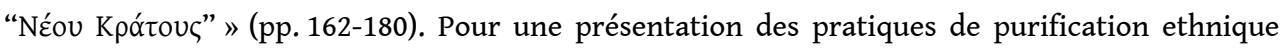

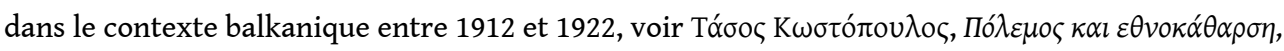

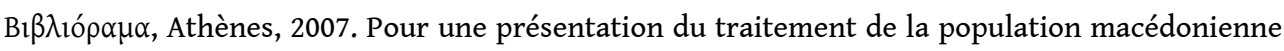

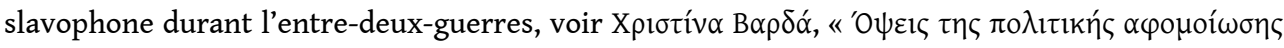

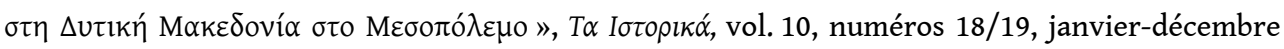
1993, pp. 151-171 (pour la période jusqu'en 1936), Philip Carabott, “The Politics of Integration and Assimilation vis-à-vis the Slavo-Macedonian Minority in Interwar Greece: From Parliamentary Inertia to Metaxist Repression", in Peter Mackridge - Eleni Yannakakis (sous la direction de), Ourselves and the others, The development of a Greek Macedonian Cultural Identity since 1912, Oxford, 1997, pp. 59-78.

18. Comme le démontre A. Elefantis, in $M \alpha \varsigma \pi \eta ́ \rho \alpha v \tau \eta v A \theta \eta ́ v \alpha$, le Front de Libération Nationale avait essayé de ressembler toutes les forces antifascistes, en suivant en cela la politique de coalition antifasciste des partis communistes européens. Face aux accusations de ses adversaires, l'EAM a également tenté de montrer qu'il résultait de l'union nationale de patriotes, toutes sensibilités politiques confondues, ce qui pour l'auteur semble inexact, dans la mesure où les partis traditionnels avaient délibérément refusé de participer au Mouvement de Libération Nationale. Les masses populaires qui $\mathrm{y}$ ont adhéré représentaient bel et bien une grande partie des Grecs, mais les formations politiques traditionnelles étaient à l'approche de la libération de plus en plus hostiles à cette force de résistance novatrice qui pratiquait la démocratie directe et l'autogestion et qui demandait l'organisation d'un référendum pour l'abolition de la

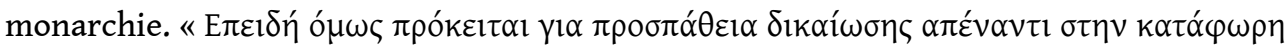

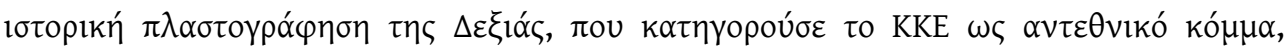

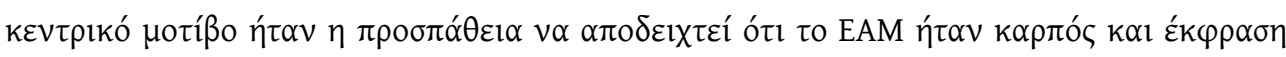

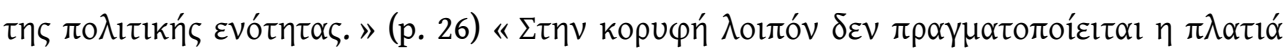

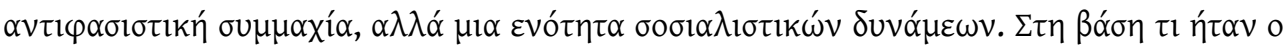

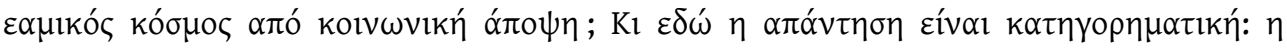

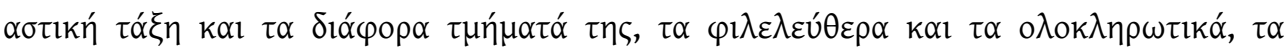

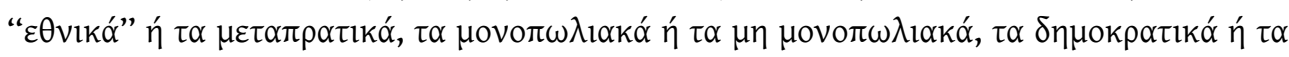

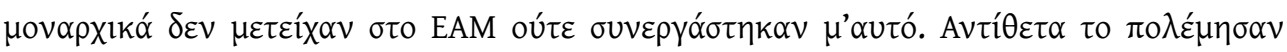

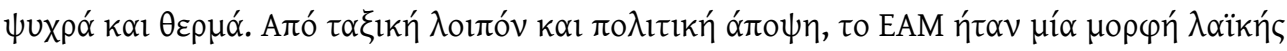

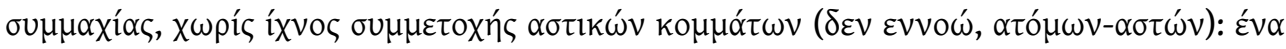

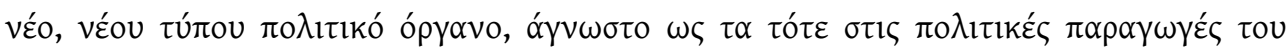

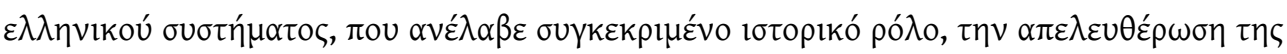

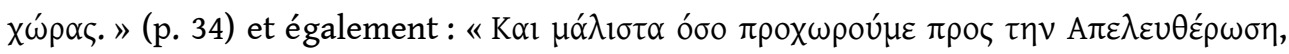

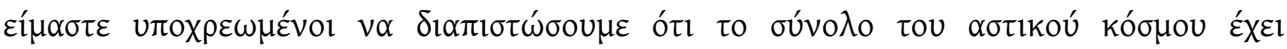




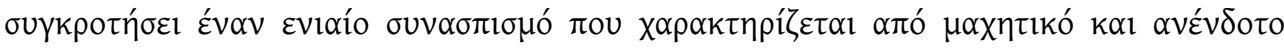
$\alpha \nu \tau \imath \varepsilon \alpha \mu \imath \sigma \mu o ́ . ~ »($ p. 28).

19. Pendant la période de l'occupation, la population macédonienne a connu deux sorts bien distincts, la région de la Macédoine de Grèce ayant été divisée en deux : la partie occidentale administrée par l'armée allemande et italienne, en étroite collaboration avec le gouvernement d'Athènes et la partie orientale, sous tutelle bulgare. Dans la partie bulgare, le gouvernement fasciste a inauguré une politique de purification ethnique à l'encontre des populations grecques, à l'image de ce que le gouvernement de Metaxás avait fait précédemment contre les minorités, tandis que dans la partie allemande, les autorités nazis aidées par des milices d'extrême droite, ont essayé de retourner au statu quo de Metaxás tout en attisant les conflits interethniques. Cf.

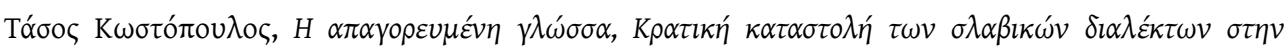

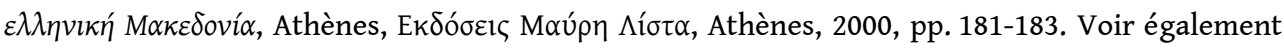

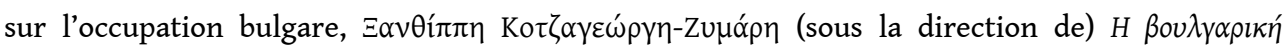

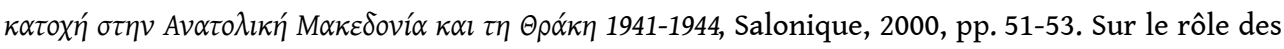

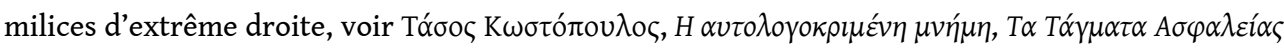

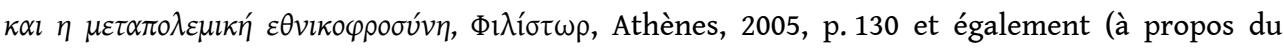

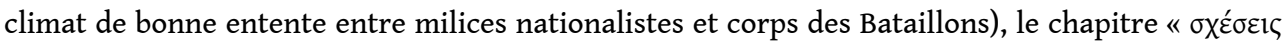

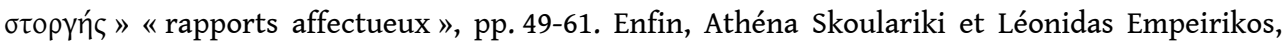

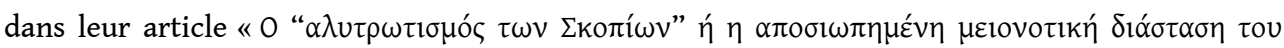

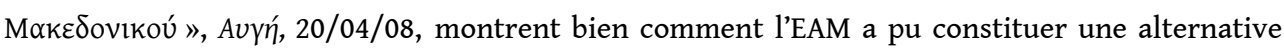
identitaire possible pour des Slavophones lésés par le gouvernement grec mais idéologiquement

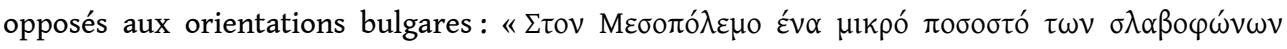

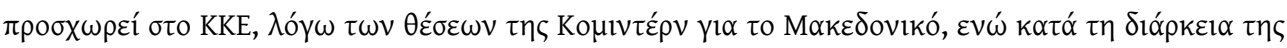

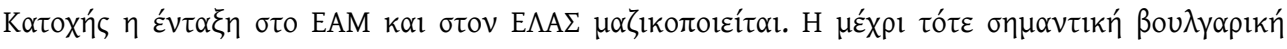

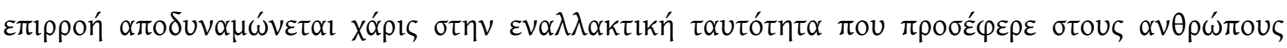

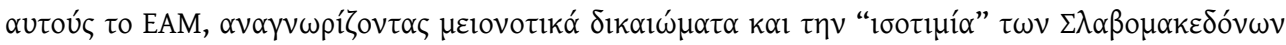

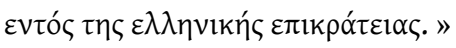

20. Le 5 mars 1943, les autorités italiennes créent «le comité révolutionnaire bulgaromacédonien » et jusqu'en avril 1943, elles recrutent environ 1600 slavophones dans une milice (Ohrana) qui s'oppose aux maquisards. Après le départ des Italiens en août 1943 et la défaite des forces de l'axe, l'été suivant, cette organisation se dissout. Cf. Tasos Kostopoulos,

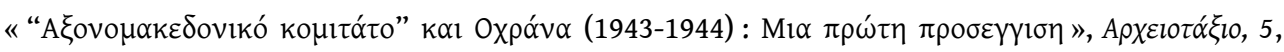
2003, 40-51. Les différentes milices et «organisations de résistance " nationalistes, de fait collaborationnistes constituent une zone grise, perméable aux « métamorphoses ovidiennes » et autres changements de bord. Il ne s'agit en aucun cas d'une spécificité macédonienne, les nazis ont recruté des hommes pour former leurs bataillons de sécurité dans la population grecque. Les différents gouvernements grecs pendant et après la guerre civile ont cherché à afficher leur appartenance idéologique au monde « libre », antifasciste et antitotalitaire, malgré des pratiques policières et judiciaires autoritaires, résolument contraires aux droits de l'homme. Dans ce contexte, les gouvernements des années 50 et 60 ont essayé de réinventer ou d'exacerber le rôle de la résistance nationaliste et de la désolidariser de l'action des bataillons de sécurité et autres milices terroristes malgré des liens bien établis entre les deux types de formations. Ils ont également tenté de passer sous silence les exactions commises contre les civils par les collaborateurs des Allemands, de nier la subordination des bataillons de sécurité à l'occupant et même de présenter les représailles des Allemands contre la population civile comme une conséquence directe et presque légitime face à l'action des Résistants de l'EAM (Souvent, on renversait le rapport de forces réel pour présenter les Allemands comme assistant les Bataillons de sécurité dans leur lutte anticommuniste.) Pour justifier l'action des bataillons de sécurité, l'historiographie officielle a essayé de mettre en avant le caractère provisoire de leur 
collaboration avec les Nazis, l'absence d'action concrète contre les alliés britanniques et le passé nationaliste et « héroïque » de leurs dirigeants (révélé antérieurement par des actes de violence perpétrés contre les populations slaves du Nord de la Grèce). Leur engagement serait alors motivé par le seul souci de protéger « le régime en place » et « l'intégrité nationale » du pays. (Cf.

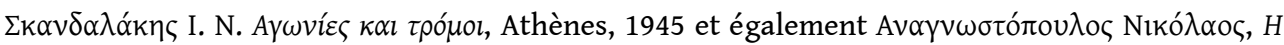

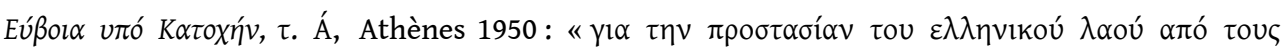

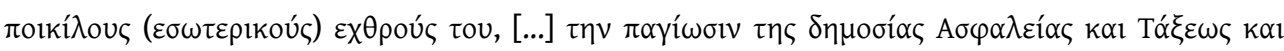

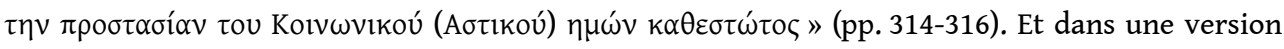
plus politiquement correcte, Evangelos Kofos, Nationalism and Communism in Macedonia, Salonique, 1964, pp. 128-131 et 134-135.) Dans la mémoire officielle, il s'agissait de présenter les bataillons comme un mouvement de défense légitime qui aurait anticipé la guerre civile en diagnostiquant à temps la dangerosité de l'EAM comme organisation terroriste.

La perception des bataillons de sécurité évolue dans le temps pour passer d'une phase de silence gêné ,voire de pure condamnation juste après la guerre, à une déformation de la réalité historique et à une glorification sans précédent lors de la dictature des colonels. Pendant la démocratisation du pays, l'évocation de ces corps disparaît des discours de mémoire tout comme l'idéologie de la loyauté nationale qui perd sa valeur d'échange.«

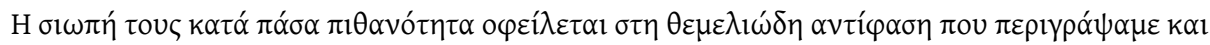
$v \omega \rho i ́ \tau \varepsilon \rho \alpha-\alpha v \alpha ́ \mu \varepsilon \sigma \alpha \sigma \tau \alpha$ «

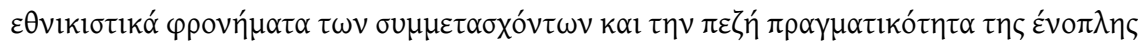

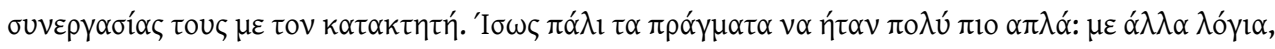

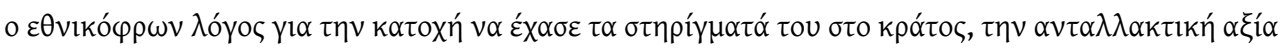

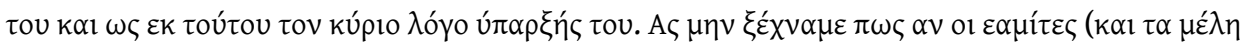

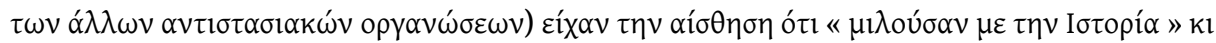

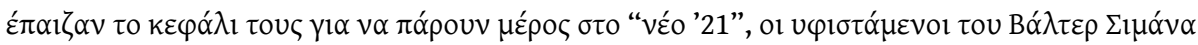

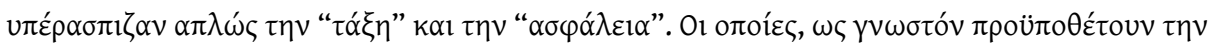

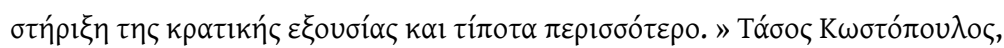

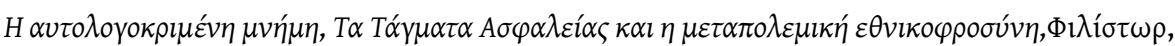
Athènes, 2005 (p. 159)

21. Les anciens cadres de l'EMEO de l'entre-deux-guerres ont hésité entre les mouvements de résistance grec et yougoslave. Le rôle de Tempo a été déterminant dans la mobilisation des

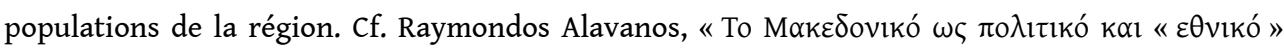

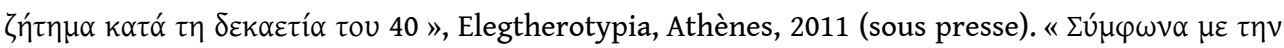

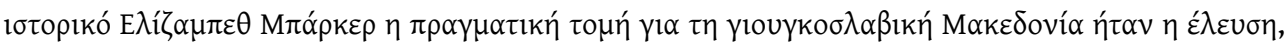

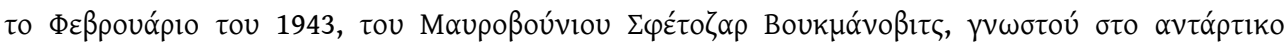

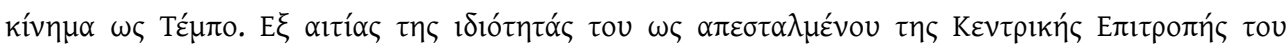

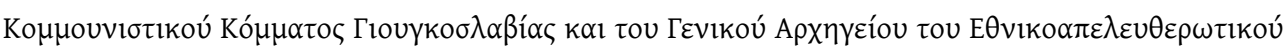

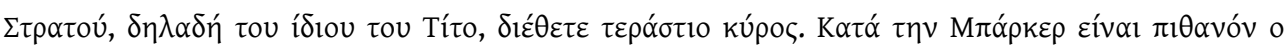

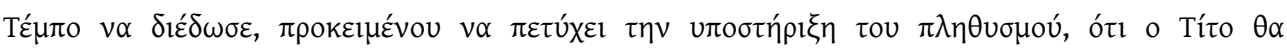

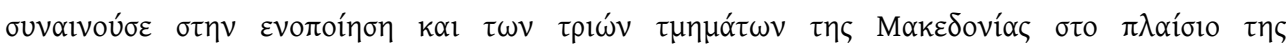

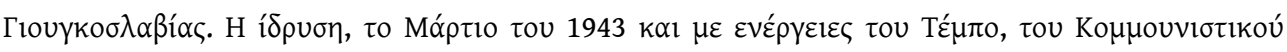

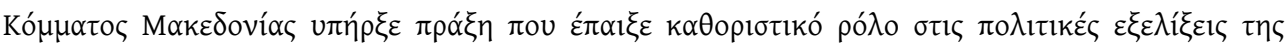

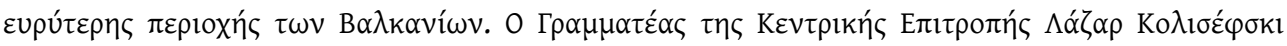

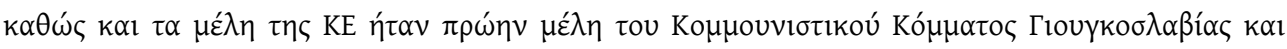

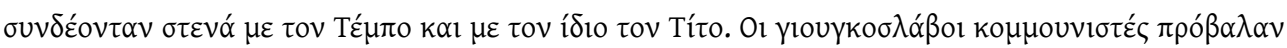

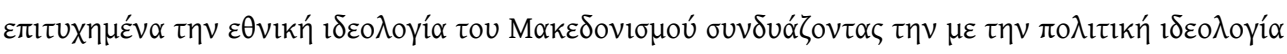

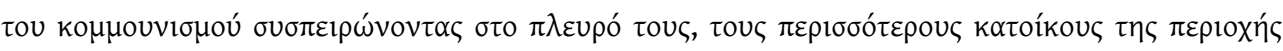

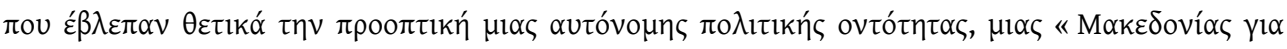




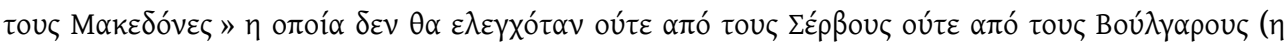

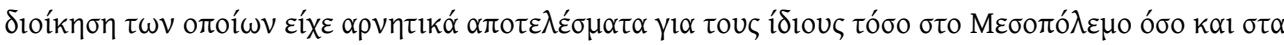

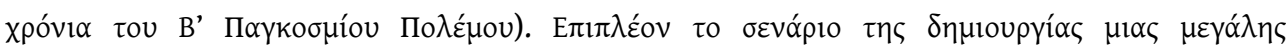

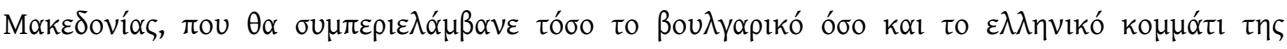

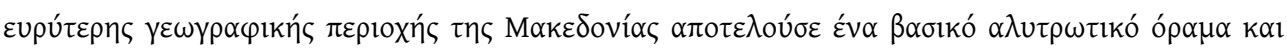

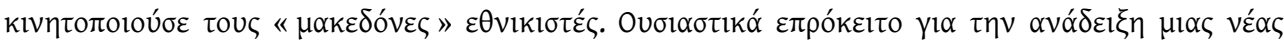

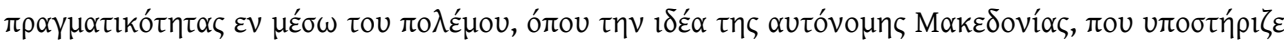

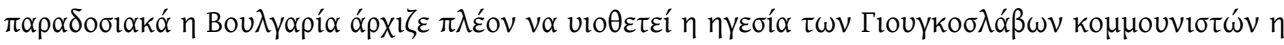

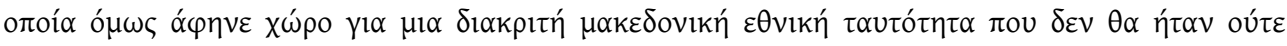

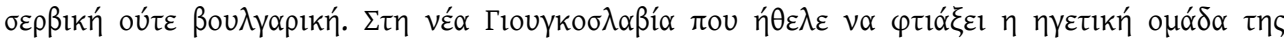

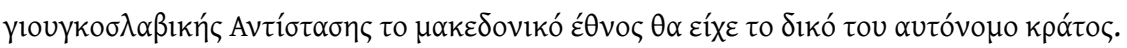

22. SNOF : (СЛАВЈАНОМАКЕДОНСКИ НАРОДНО ОСЛОБОДИТЕЛЕН ФРОНТ) Front de libération du peuple slavomacédonien. Ce mouvement loin d'être un phénomène marginal trouve ses racines idéologiques dans l'engagement de l'entre-deux-guerres des communistes macédoniens, tels que Tsipas, Terpovski, Galabov, Hadjiganev, Ourumov Cf. Institute of National History, A history of Macedonian People, Skopje, 1979, pp. 308-311.

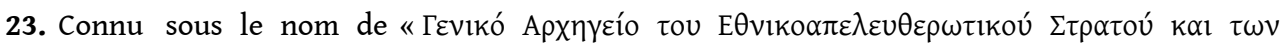

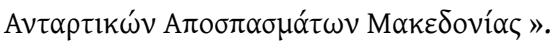

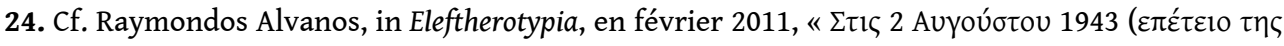

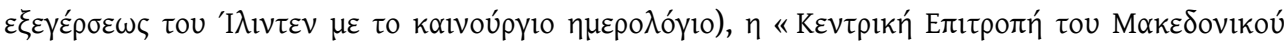

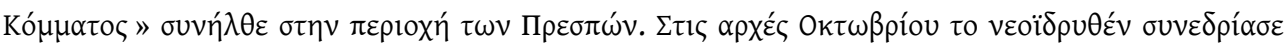

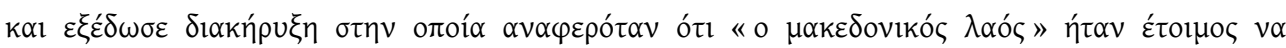

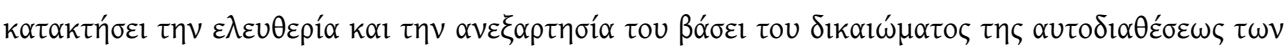

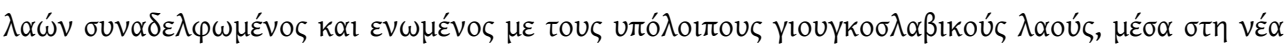

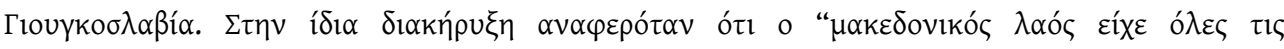

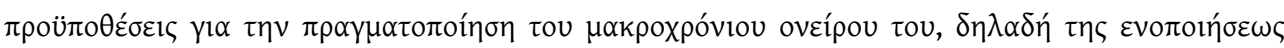

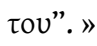

25. Sur les positions de Tito, voir Elisabeth Barker, "Macedonia, its place in Balkan power politics", 1950, pp. 155-156.

26. Il est intéressant de relever qu'en Grèce, on a moins reproché aux communistes grecs le pacte germano-soviétique (dans la mesure où ces derniers se sont rapidement associés au "non » de Métaxas) et on les a bien plus soupçonnés de connivence avec « les ennemis slaves ».

27. Sur le rôle du SNOF, l'engagement des activistes macédoniens et leurs relations avec les Partis

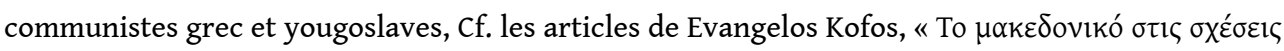

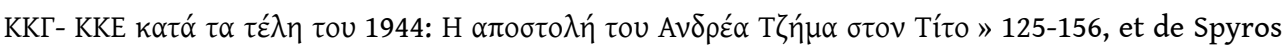

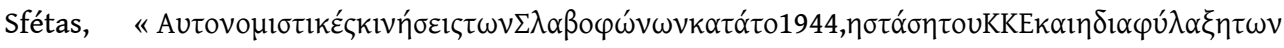

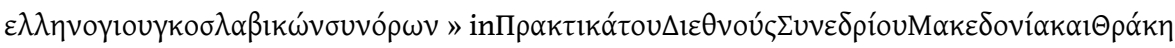

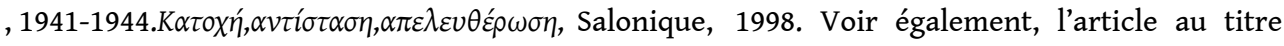
évocateur de Andrew Rossos, "Incompatible Allies: Greek communism and Macedonian nationalism in the Civil War in Greece, 1943-1949" The journal of Modern History 69 (3/1997), pp. 41-76. Pour une approche finalement représentative de l'historiographie grecque officielle, voir également Evangelos Kofos, Nationalism and communism in Macedonia, IMXA, Salonique, 1964,

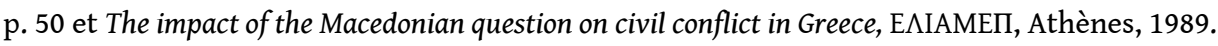

28. Pour l'enseignement de la langue macédonienne pendant «les années orageuses » de la

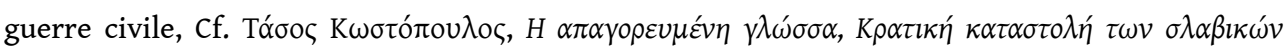

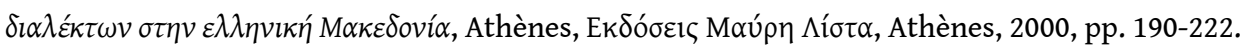

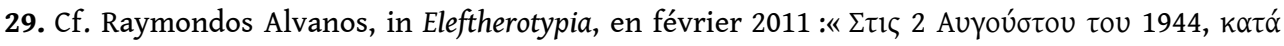

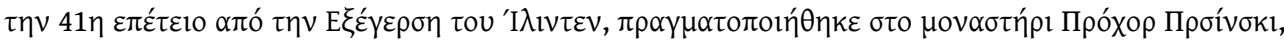

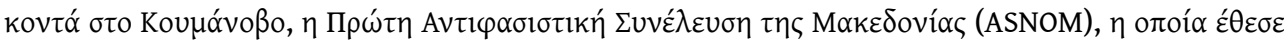




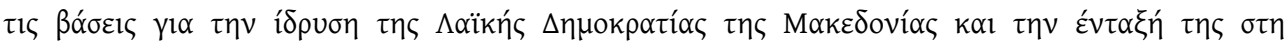

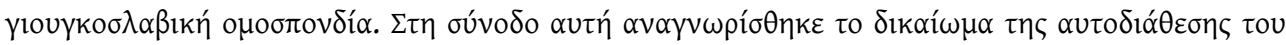

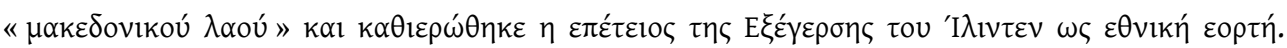

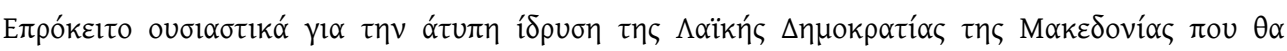

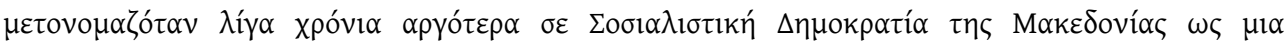

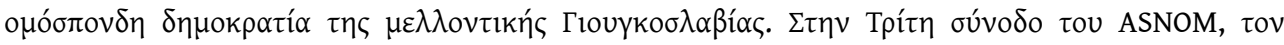

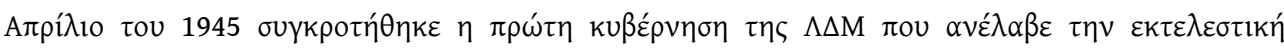

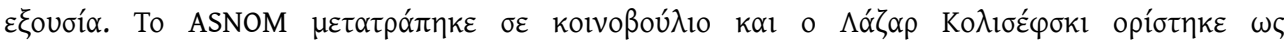

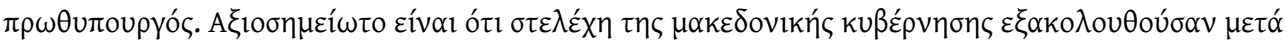

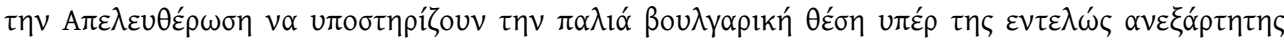

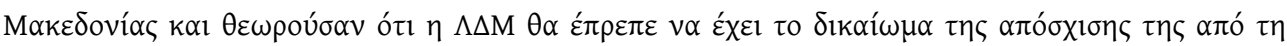

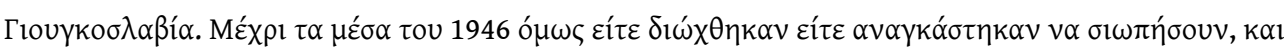

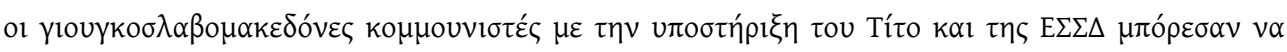

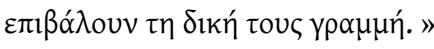

30. Cf. Sur les rapports entre Bulgarie, Grèce et Macédoine, voir l'article de Raymondos Alvanos,

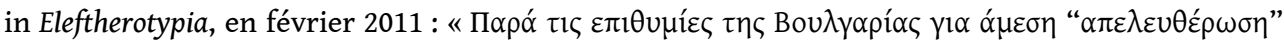

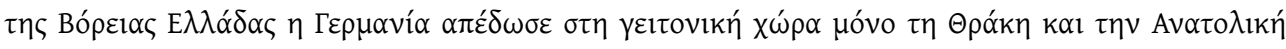

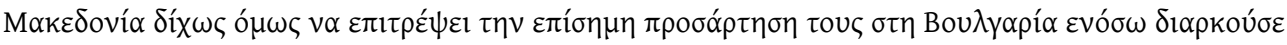

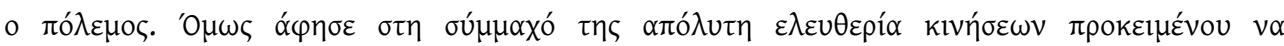

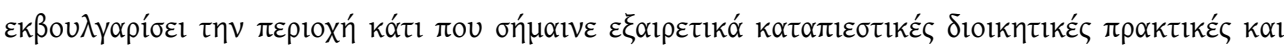

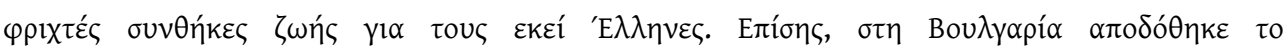

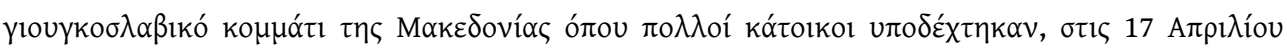

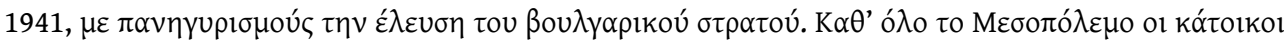

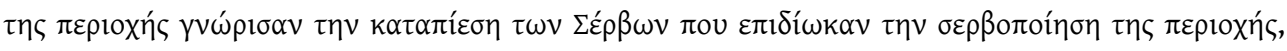

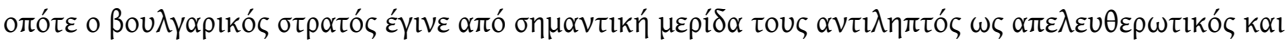

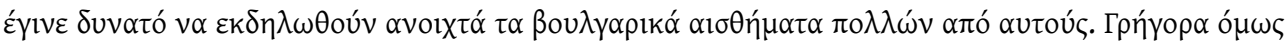

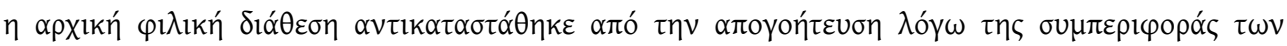

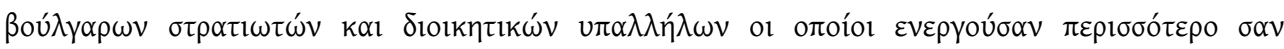

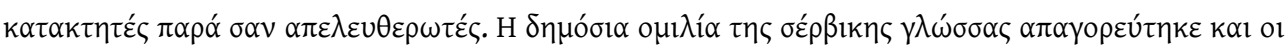

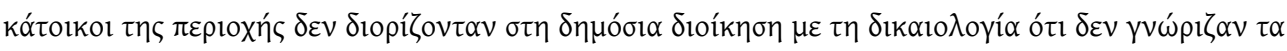

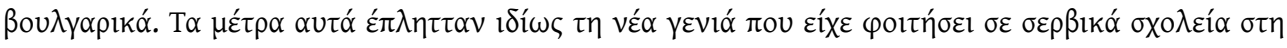

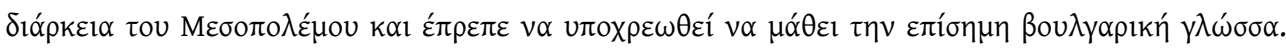

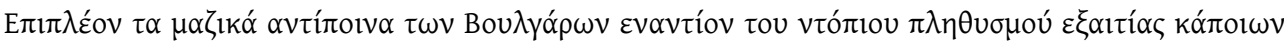

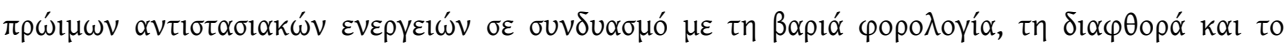

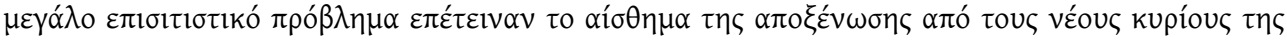
$\pi \varepsilon \rho 10 \chi \eta ́ \varsigma »$.

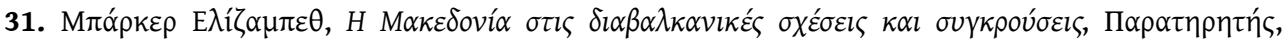

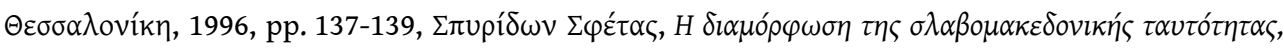

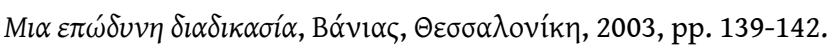

32. Dans la correspondance des nationalistes I. Zografos et F. Dragoumis, que Kostopoulos a étudiée, il apparaît clairement que des nationalistes, profondément anticommunistes, regrettent ces persécutions massives qui touchent des Slavophones qui ne se seraient pas engagés du côté

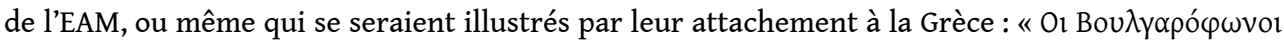

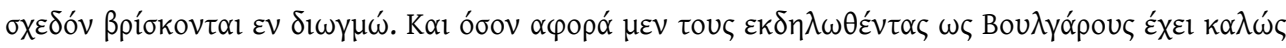

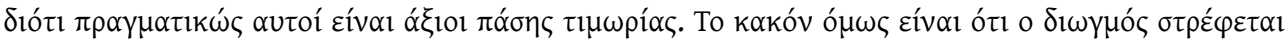

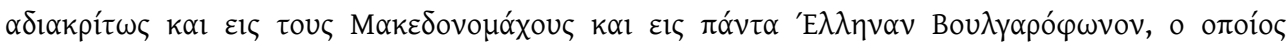

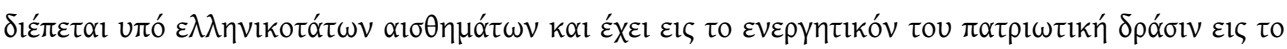

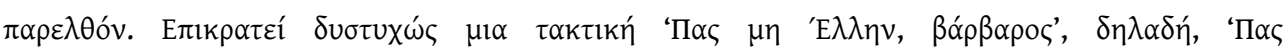




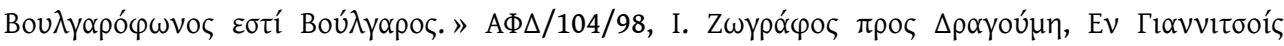

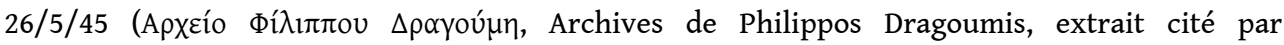

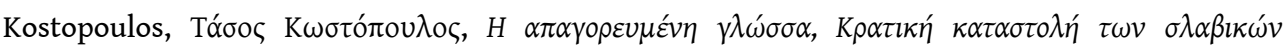

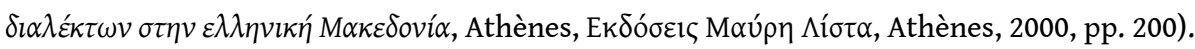

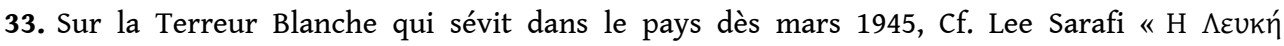

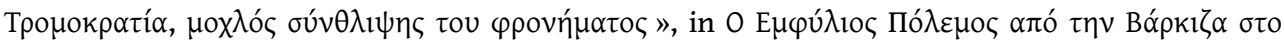

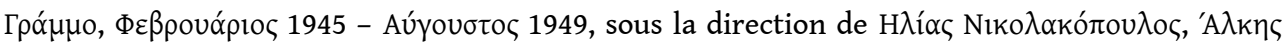

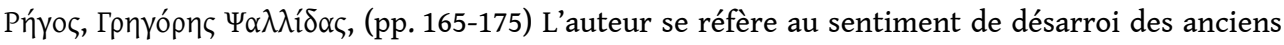
sympathisants de l'EAM face à ce que les acteurs assimilent à une « deuxième occupation » et évoque les sentiments d'injustice et de trahison ressentis par la population soumise à la Terreur

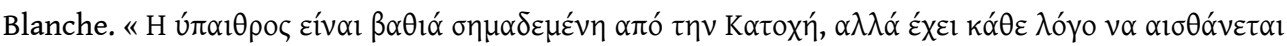

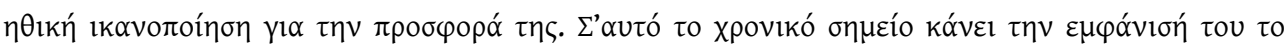

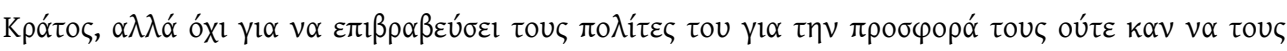

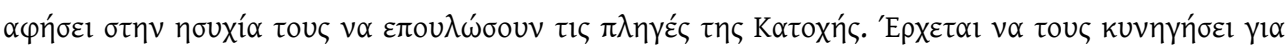

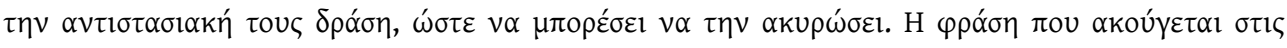

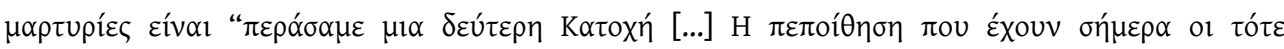

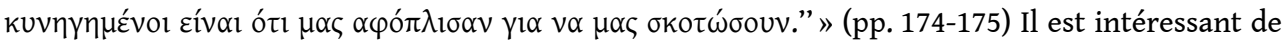
comparer l'expérience de la Terreur dans le Nord de la Grèce avec celle dans le Sud, où la question de la population macédonienne ne se pose pas. Nous aboutissons à la conclusion que la violence est similaire, toute la Grèce rurale en est touchée. Pour la Terreur Blanche dans le

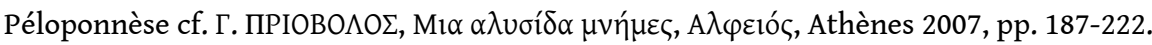

34. Les accords de Varkiza, dans la continuité de ceux du Liban et de Caserta, concomitants avec ceux de Yalta, transforment la défaite militaire de décembre en déroute politique. Comme le dit avec justesse, Christophe Chiclet, Les communistes grecs dans la guerre, L'Harmattan, coll. Histoire et perspectives méditerranéennes, Paris, 1987. «Ce ne sont plus des concessions, mais c'est une véritable reddition. Le K.K.E. perd son armée, sa police, les déserteurs des forces gouvernementales qui l'ont rejoint et sa liberté de manœuvre dans la capitale. L'article III est le plus terrible, car il laisse la porte ouverte à la criminalisation des militants politiques. Siantos tire les leçons de son échec de décembre et passe sous les fourches caudines de Leeper et de Plastiras. Le K.K.E. a sauvé ses dirigeants, ses cadres supérieurs et moyens : l'ossature du parti. Mais il livre sa base et ses compagnons de route de l'EAM à la vindicte du gouvernement légal. Ces accords, pourtant passablement avilissants et contraignants pour le Parti, ne seront même pas respectés par la droite. Les libertés individuelles et syndicales ne seront pas respectées, l'amnistie ne sera pas pleine et entière, la nouvelle armée se fera sans les Elasites, les purges civils et militaires atteindront les Eamites et très peu les collaborateurs. » (p.128) "L'élan révolutionnaire des masses était stoppé. Après Varkiza, le Parti ne l'a pas ranimé. Il laissa ses militants se faire assassiner, battre, emprisonner par la terreur « monarcho-fasciste ». Il ne leur expliqua pas qu'ils étaient victimes des sphères d'influence »[...] "Les communistes de l'EAM avec leur instruction incomplète, leur étroitesse d'horizon spirituel, leur manque d'éducation culturelle, leur méfiance et leur fanatisme face aux petits bourgeois de l'EAM, ont rapidement créé un clivage dans le mouvement démocratique. Cela s'est traduit concrètement par la désertion des dirigeants socialistes et des classes moyennes, affaiblissant ainsi une organisation en but à une répression de plus en plus féroce. » (p. 150)

Sur la stratégie du Parti Communiste, Cf. Christophe Chiclet, op.cit. Les grands chapitres retracent avec brio l'histoire de la résistance, de la libération et de la guerre civile : chapitres « La tragédie de décembre», «Les accords de Varkiza", «La terreur», "la reprise du conflit» et "décomposition et défaite du K.K.E.» Cf. également, David H. Close, The Origins of the Greek Civil War, Harlow, Longman Group, 1995 ; Thanasis D. Sfikas, "War and Peace in the Strategy of 
the Communist Party of Grece, 1945-1949", Journal of Cold War Studies, 2001, n 3, p. 5-30 et Dominique Eudes, Les Kapétanios, Paris, Fayard, 1970.

35. Dans le cas macédonien, on atteint le comble du paroxysme, ce sont d'anciens collaborateurs, membres de Ochrana qui accusent des Slavophones de gauche d'avoir collaboré avec la Bulgarie. Dans toute la Grèce, les collaborateurs de Nazis sont investis de tous les pouvoirs et peuvent s'adonner à une véritable chasse aux sorcières contre les résistants.

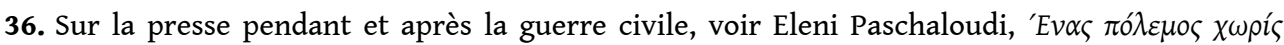

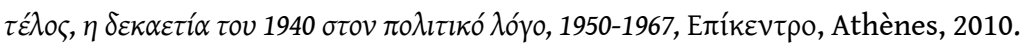

37. Konstantinos Loulos montre bien l'étendue des persécutions, épurations et autres formes d'exclusion s'inscrivant dans la continuité des pratiques de Métaxas, (1936-1940) et l'expérience

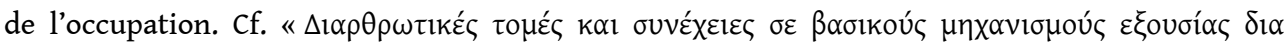

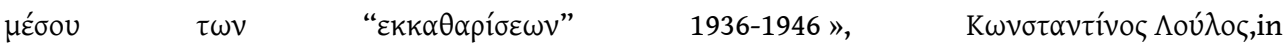

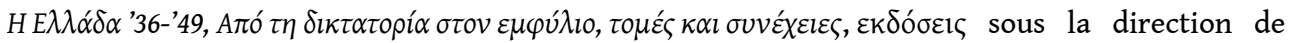

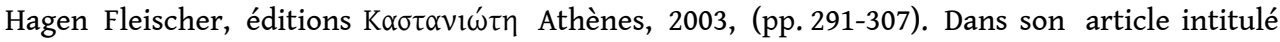

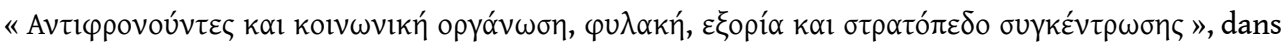
le même recueil, M.E. Kenna décrit les déportations et les incarcérations massives des vaincus (pp. 308-320).

38. L'ostracisme qui frappe les citoyens dont la «loyauté nationale» serait déficiente est manifeste dans le discours de la presse. Polyméris Voglis fait justement un rapprochement fort intéressant entre la publication massive des déclarations de repentir dans la presse et l'exclusion de la gauche du paysage politique du pays. Depuis la suppression de tous les journaux de gauche, à l'exception de Móxๆ, la presse grecque est muselée. Le seul discours audible est celui de la propagande gouvernementale qui s'extasie devant le nombre de déclarations signées et relate avec force détails les scènes d'exécutions publiques. Des photos des journaux de l'époque montrent des têtes coupées, suspendues sur des poteaux ou triomphalement présentées par les auteurs de la décapitation. Les mêmes journaux publient des déclarations de repentir "spontanées", en prenant bien soin de signifier que la seule alternative à la mort est la

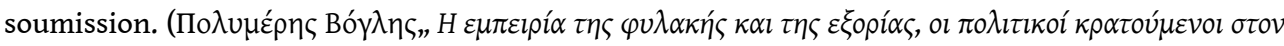
$\varepsilon \mu \varphi v \lambda_{10} \pi \operatorname{có}_{\varepsilon \mu \rho}$, Athènes, $\mathrm{A} \lambda \varepsilon \xi \xi_{\alpha} v \delta \rho 1 \alpha, 2004, \mathrm{pp} .126-132$. Ibidem, p. 129. À titre, d'exemple, P. Voglis cite l'exécution de Diamantis dans le journal Akropolis du 30 octobre 1947 et la publication de Daily Mirror, 10/11/1947, où des hommes armés portent les têtes coupées de Tzavelas et de Vélouchiotis.) La presse nationaliste demande la déportation de « ces Sudètes de la Grèce ", leur

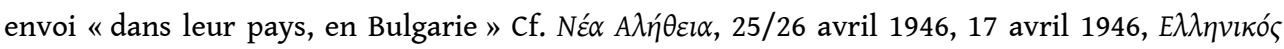
Boppós 12 avril 1946, 18 avril 1946, 26 avril 1946 et 2 juillet 1946. Pour certains journalistes, ces

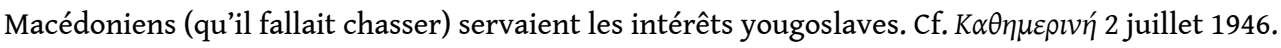
Pour se faire une idée du discours sur la purification ethnique à travers la presse, voire les

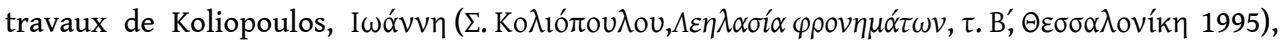
eux-mêmes marqués par un militantisme nationaliste qui cautionne les politiques d'assimilation forcée et/ou de purification ethnique quand il ne se contente pas de les nier. Dans deux articles

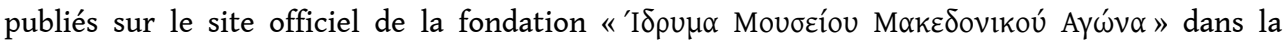
rubrique Histoire de la Macédoine, l'auteur commence par nier la politique de purification ethnique menée par Métaxas avant de justifier l'attitude de l'état grec pendant la guerre civile en expliquant par exemple que d'autres grandes nations européennes ont mené des politiques

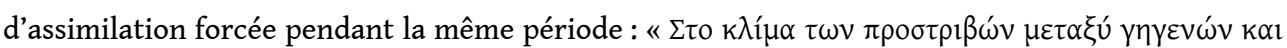

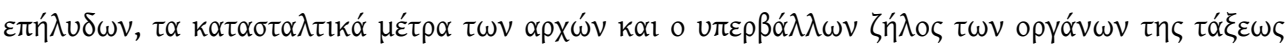

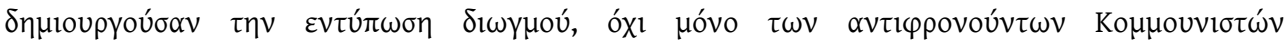

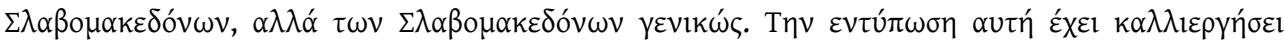

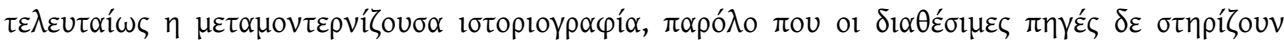

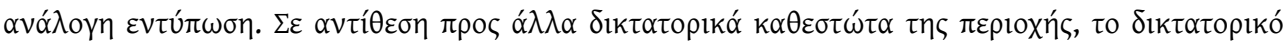




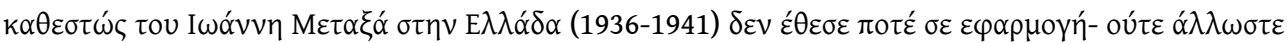

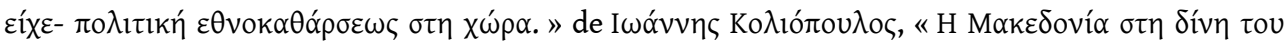

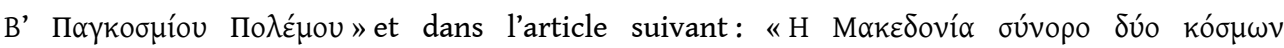

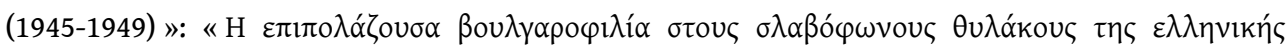

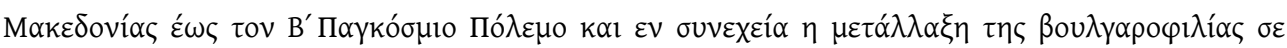

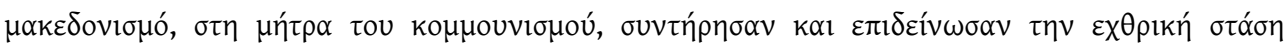

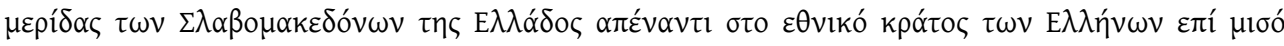

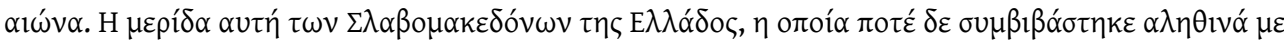

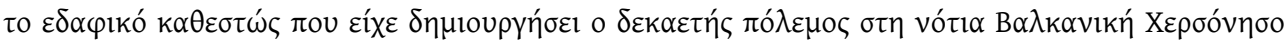

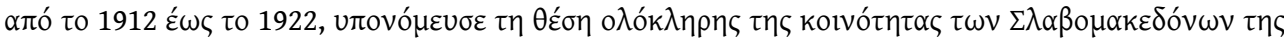

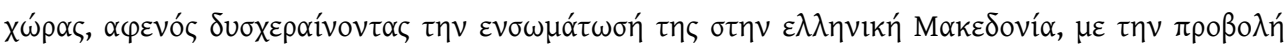

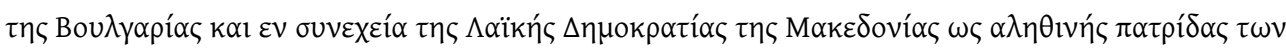

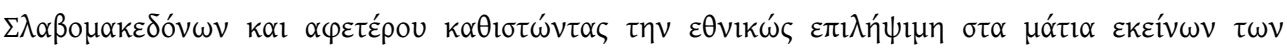

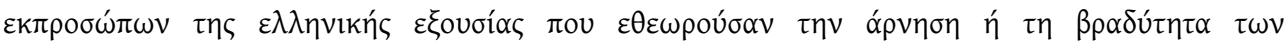

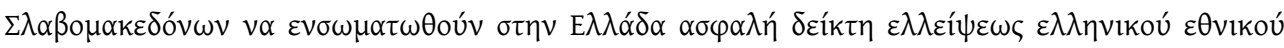

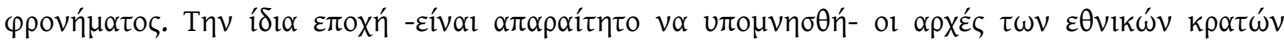

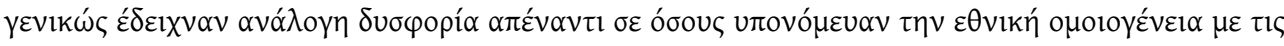

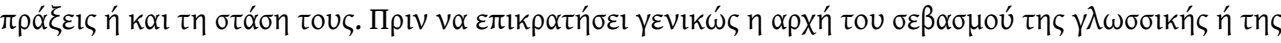

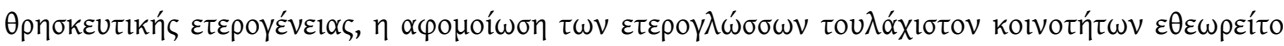

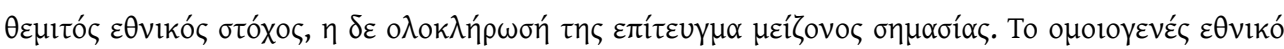

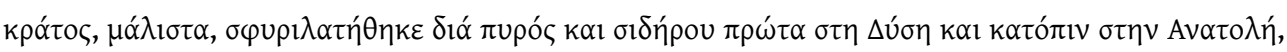

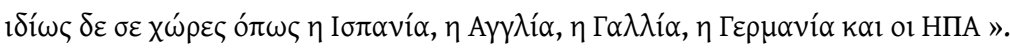

39. Le discours des vainqueurs de la guerre civile fait appel à l'idéologie de la "loyauté nationale » pour réinterpréter l'expérience de l'occupation et de la guerre civile et aboutir à une reconstruction autocensurée de la mémoire officielle et de la praxis historiographique. Pour une

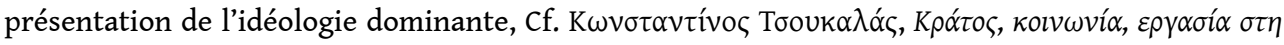

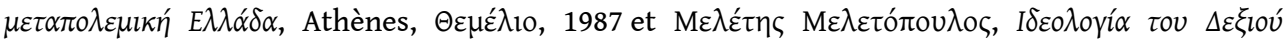

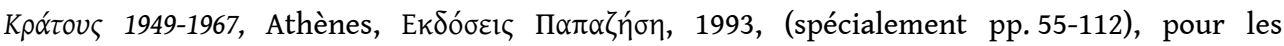
dimensions sociales du phénomène dans une région particulière, la Macédoine de l'Égée, $\mathrm{Cf}$.

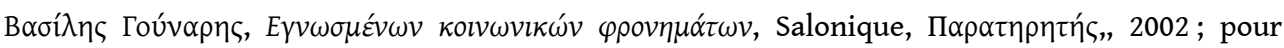

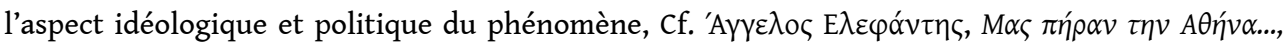

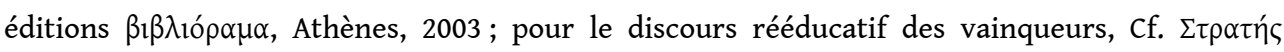

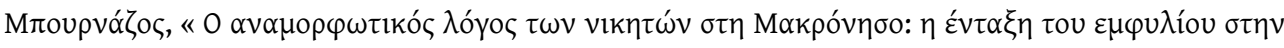

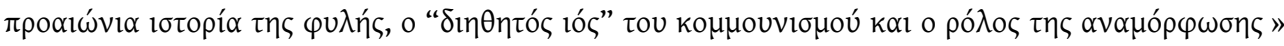

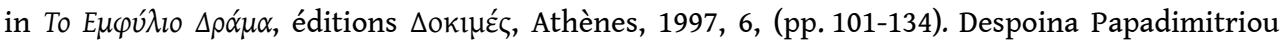
propose une étude fort intéressante de la continuité et de la rupture dans le discours de

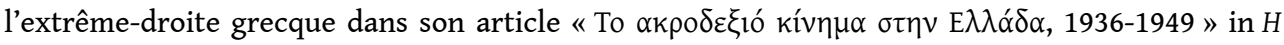

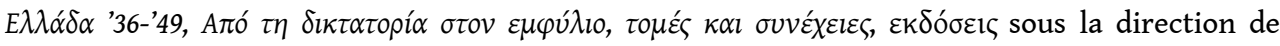

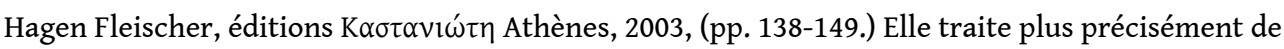

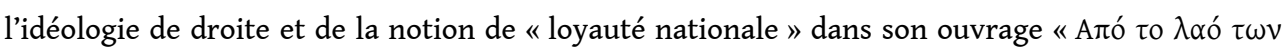

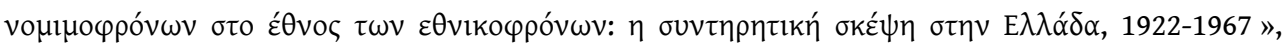
Athènes, $\Sigma \alpha \beta \beta \alpha ́ \lambda \alpha \varsigma, 2006$. Spyros Marketos fait remonter les origines de ce discours nationaliste à

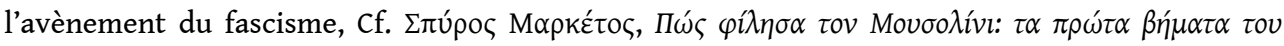

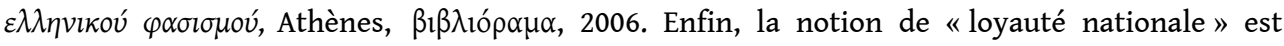

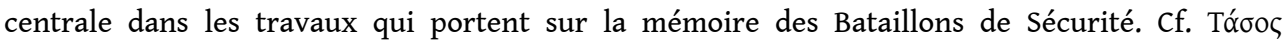

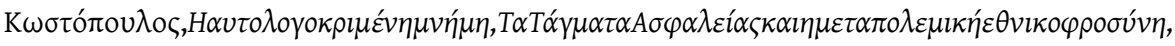

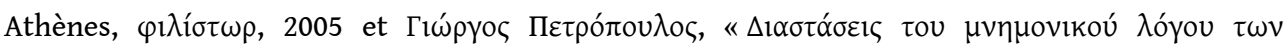

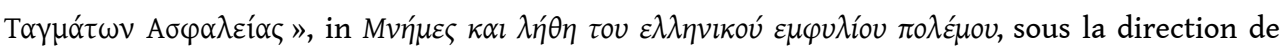
Riki Van Boeschoten, Tasoula Vervenioti, Eutychia Voutyra, Vassilis Dalkavoukis et Konstantina 


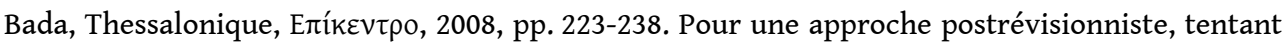
de réhabiliter ou de faire l'apologie (c'est selon) de la pensée nationaliste, Cf. $\Sigma \tau \alpha \dot{\theta} \theta \eta \varsigma$ K $\alpha \lambda u ́ \beta \alpha \varsigma$ \&

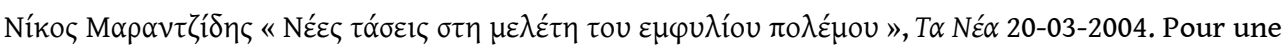
présentation en langue anglaise de cette nouvelle tendance, qui renoue avec des schémas explicatifs bien connus, Cf. Nikos Marantzidis \& Giorgos Antoniou, "The Axis Occupation and Civil War: changing trends in Greek historiography, 1941-2002", Journal of Peace Research, 41/2

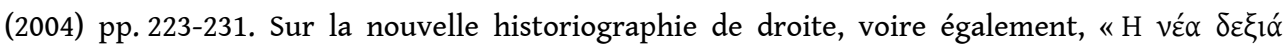

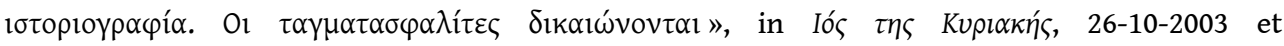

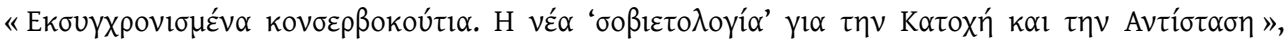

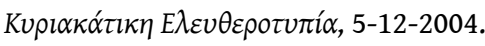

40. Cf. Le témoignage d'une femme, elle-même élevée (et endoctrinée) dans les orphelinats de la Reine Frédérika, qui omet toute référence à la langue macédonienne du village dont elle est

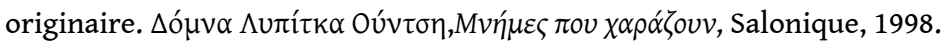

41. Ces organisations d'inspiration communiste luttent pour la reconnaissance de l'identité macédonienne, elles se reconnaissent dans les revendications sociales et politiques du PCG (KKE) et du PC yougoslave et s'opposent parmi les premières aux accords de Varkiza.

42. Pendant le conflit, la guerre civile était qualifiée de «lutte contre le fascisme» ou de second

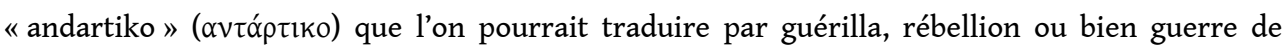
maquis, dans la continuité du premier "andartiko» qu'était la résistance. Cette filiation revendiquée n'est pas fortuite, les forces de l'Armée Démocratique s'inscrivaient dans la continuité de l'ELAS, bras armé de l'EAM et leur idéal sociétal était celui pratiqué dans la Grèce Libre par l'EAM. En Grèce comme ailleurs en Europe, l'antifascisme avait pris la forme d'un mouvement de résistance contre les Nazis tout en acquérant les traits d'un combat à caractère social voire d'une lutte des classes et en renforçant le poids des partis communistes, principaux pôles d'opposition à l'occupant. Pour Elefantis, la résistance antifasciste d'inspiration communiste, qu'il oppose à la résistance probritannique, a formé un peuple antifasciste européen et a créé une idéologie fédératrice qui ne perdra de sa force qu'après l'usure des régimes

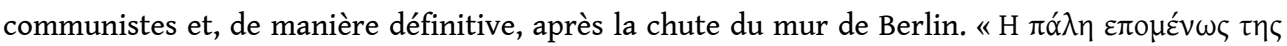

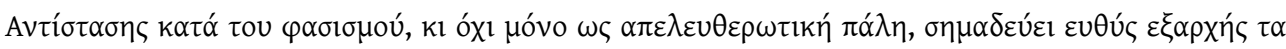

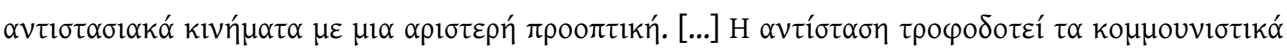

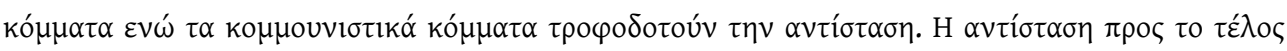

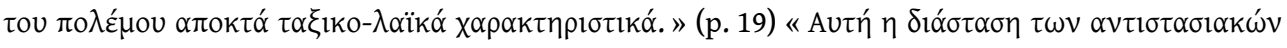

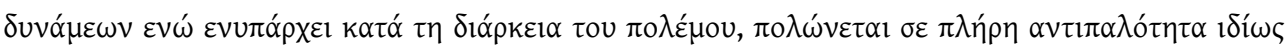

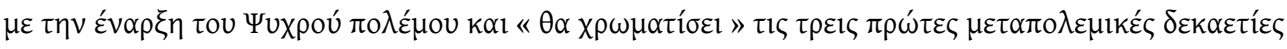

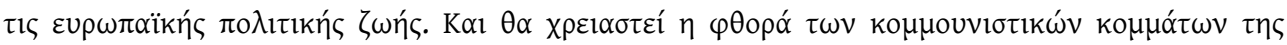

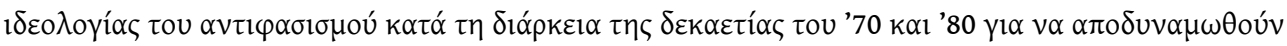

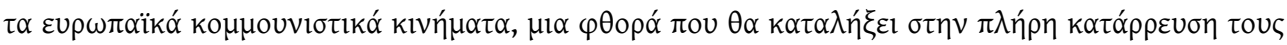

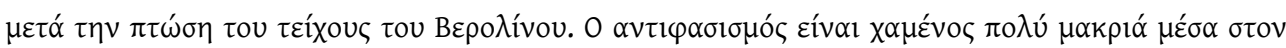

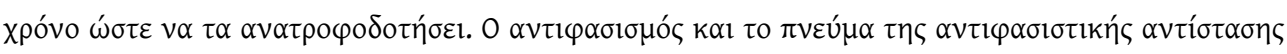

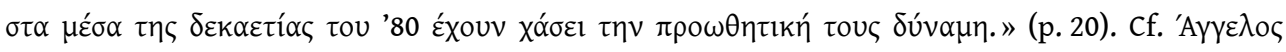

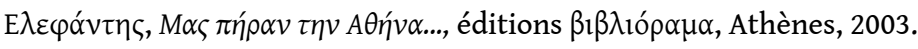

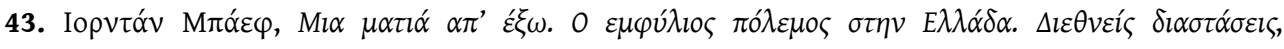

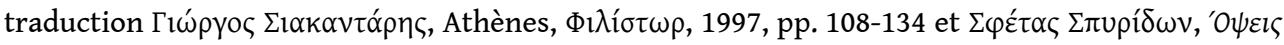

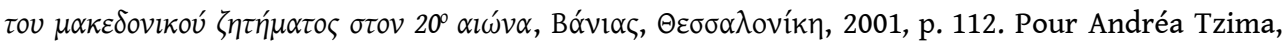

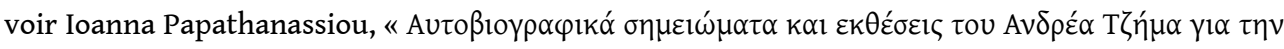

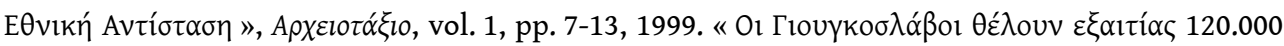

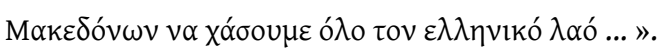

44. Nikos Alivizatos, ibidem (p. 393) Pour une présentation détaillée (quoique clairement

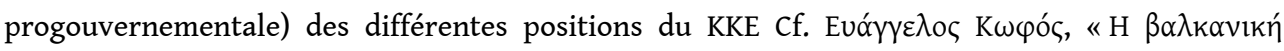




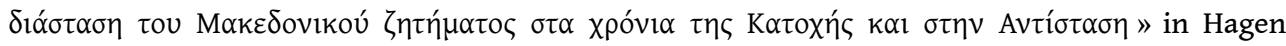

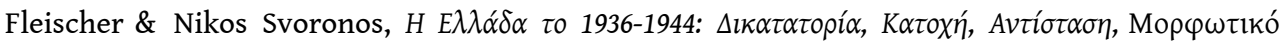

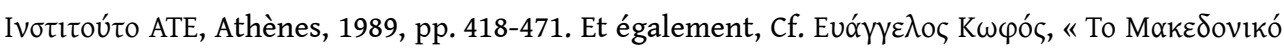

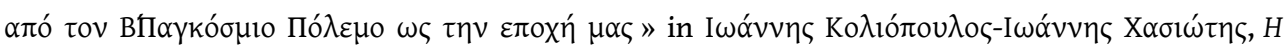

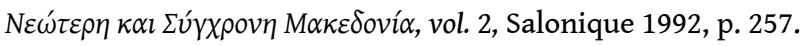

45. Pallis, Alexandros (1925a), "Racial migrations in the Balkans during the years 1912-1924", The Geographical Journal, 66/4 (du 10/1925), pp.315-31; Jacques Ancel, La Macédoine. Son évolution contemporaine, Paris 1930 ; André Wurfbain, L'échange gréco-bulgare des minorités ethniques, Paris 1930 ; Stephen Ladas, The exchange of minorities, N. York 1932; Dimitri Pentzopoulos, The Balkan exchange of minorities and its impact on Greece, Paris - Le Hague 1962.

46. Pour une liste des estimations secrètes des divers services administratives, militaires ou policières de l'époque: Tasos Kostopoulos, “Counting the 'Other': Official Census and Classified Statistics in Greece (1830-2001)”, Jahrbücher für Geschichte und Kultur Südosteuropas, 5 (2003), pp. 73-74.

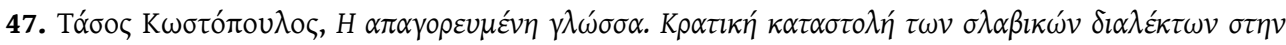
$\varepsilon \lambda \lambda \eta v \imath \kappa \eta ́$ M $\alpha \kappa \varepsilon \delta o v i ́ \alpha$, Athènes 2000, pp. 73-80.

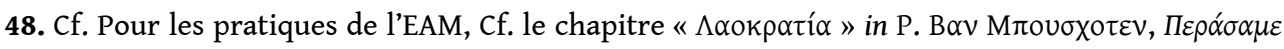

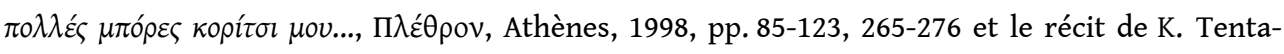

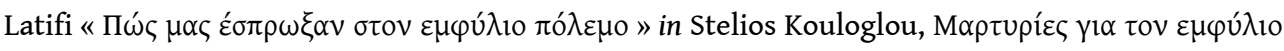

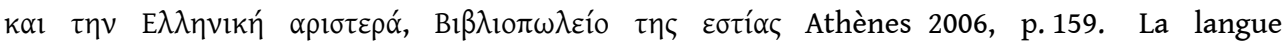
macédonienne a été de nouveau enseignée et de nombreuses publications en macédonien ont vu le jour : НЕПОКОРЕН, ЕДИНСТВО, ЗОРА, ПОБЕДА.

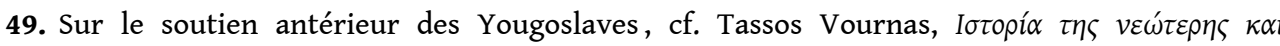

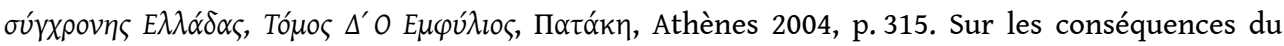
conflit Staline-Tito ibid, pp. 230, 306, 366.

50. Et jusqu'à aujourd'hui le Parti communiste reste perplexe devant ses contradictions, il est en quelque sorte incapable d'appréhender cette question dans la logique internationaliste qu'il avait adoptée.

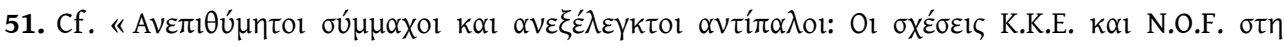

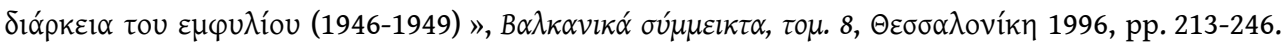
Sur les points de divergence et les axes de convergence entre le Parti Communiste grec, le Parti

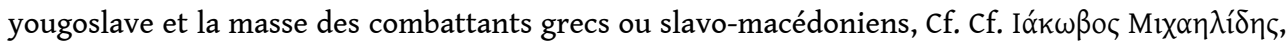

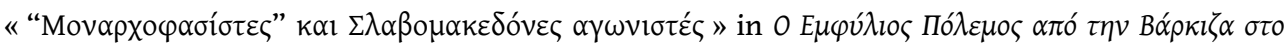

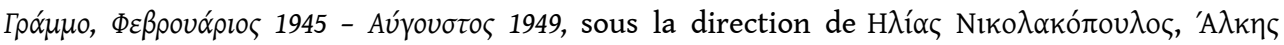

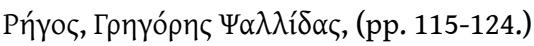

52. Pour décrire l'exclusion et le déni qui frappent les Macédoniens, Athéna Skoulariki dit avec beaucoup de justesse que « la réponse a été double : au niveau international l'altérité linguistique et culturelle d'une partie de la population a été niée ; à l'intérieur, la politique d'assimilation forcée a repris des années 50 et jusqu'à la fin des années 70. Cf. Athéna Skoulariki, «La Crise Macédonienne (1991-1995) et la question des slavophones en Grèce. » Balkanologie VII [1], juin 2003, pp. 147-156. (p. 150)

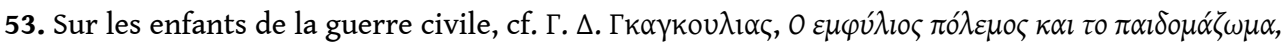

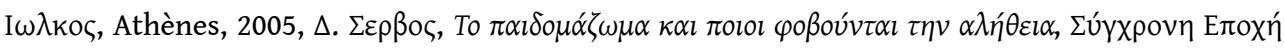
Athènes, 2004. Voir également les nombreux travaux de Riki Van Boeschoten sur la question.

54. Le cas d'enfants d'abord envoyés dans des camps de concentration ou des prisons avec leurs mères, pour en être séparés quelque temps après est magistralement traité dans le livre de Mando Dalianis-Karambatzakis, Children in Turmoil during the Greek Civil War 1946-49: Today's Adults,

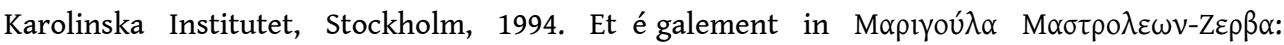

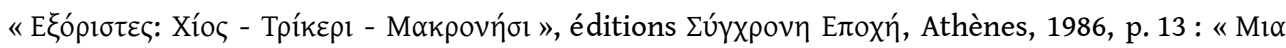




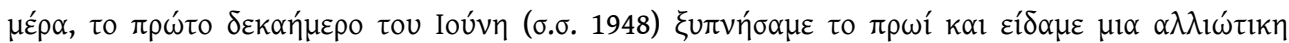

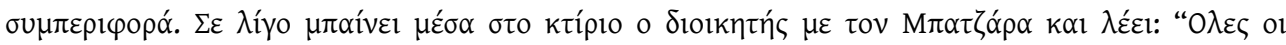

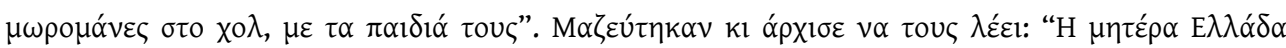

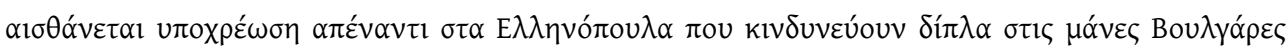

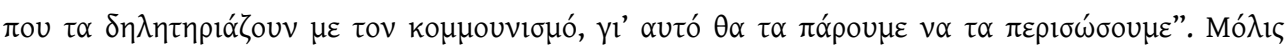

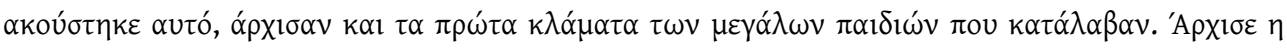

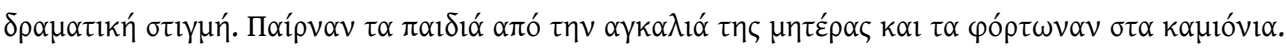

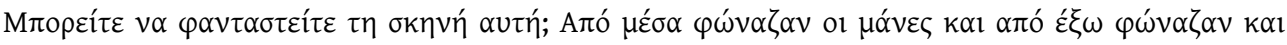

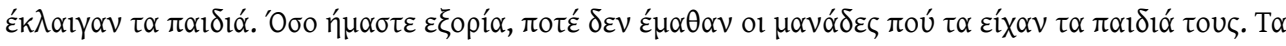

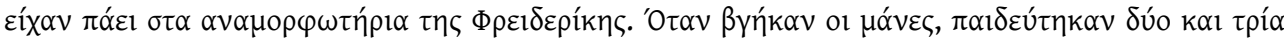

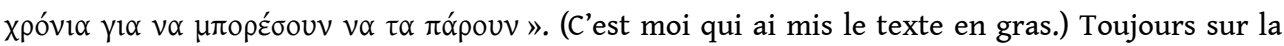
violence dont les mères et leurs enfants sont victimes, Cf. le témoignage d'Ourania Staveri

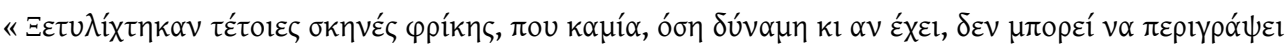

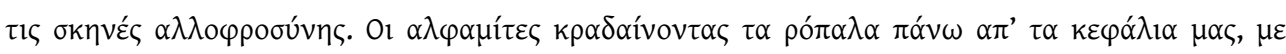

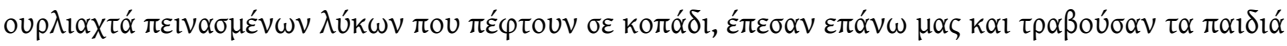

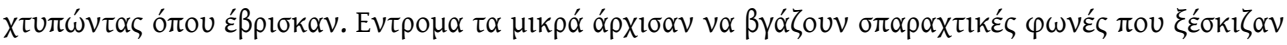

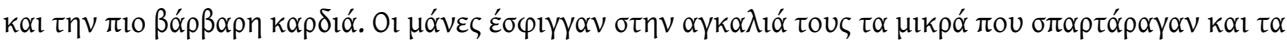

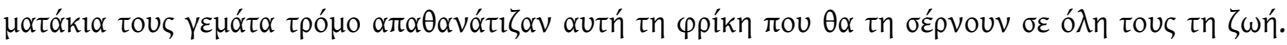

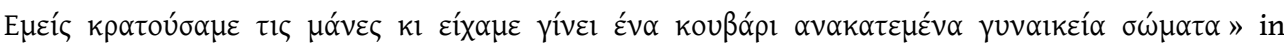

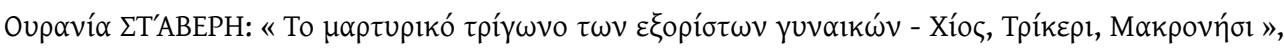

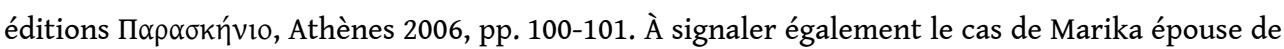
Bartziotas qui refuse de signer sous la torture et finit par céder quand on la menace de lui

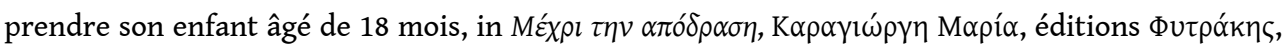
Athènes, 1989, pp. 161-162.

55. Sur l'ampleur de l'exode des populations macédoniennes de 1913 à la période juste après la fin de la guerre civile grecque, cf. l'article de Skoulariki et Empeirikos op.cit. : « A

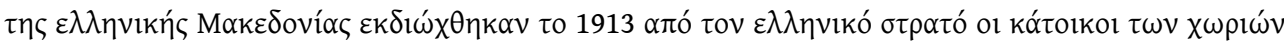

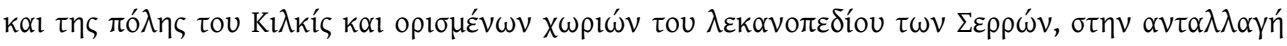

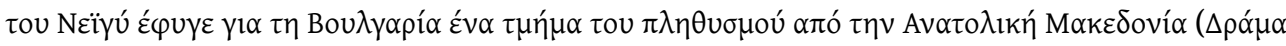

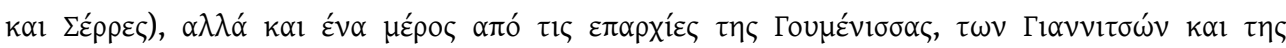

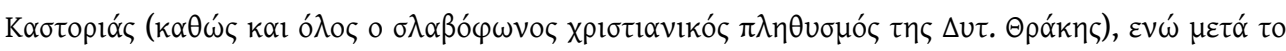

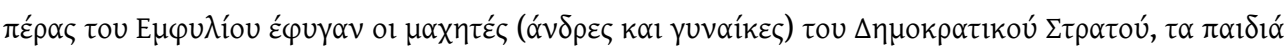

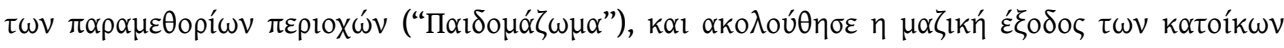

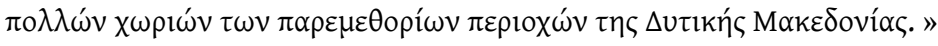

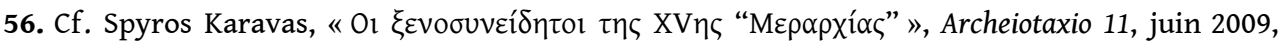

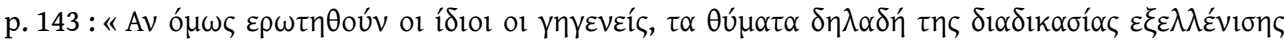

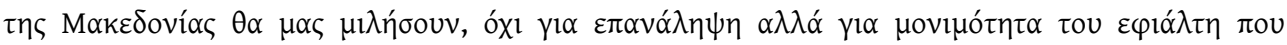

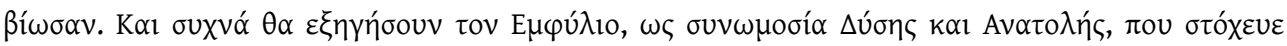

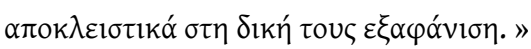

57. Cf. A la libération, le gouvernement grec a eu besoin des hommes des bataillons pour organiser la répression des anciens résistants et former l'appareil coercitif qui servirait pendant la guerre civile et jusqu'à la chute de la dictature des colonels. Or, les bataillons de Sécurité étaient très peu appréciés par la société grecque dans son ensemble et la place de choix qui leur avait été accordée, a été difficilement acceptée même au sein des organisations nationalistes. Pour Tasos Kostopoulos, la mémoire officielle a dû censurer ou limiter cette évocation et essayer plutôt de puiser la légitimité des nouveaux maîtres dans les gouvernements en exil au Moyen-

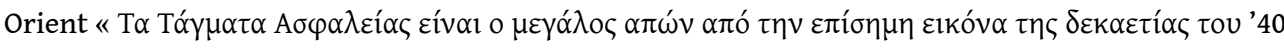

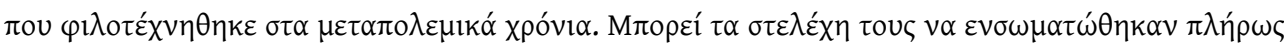

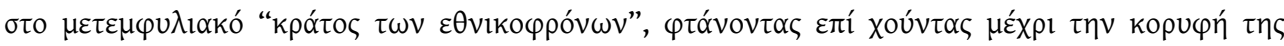




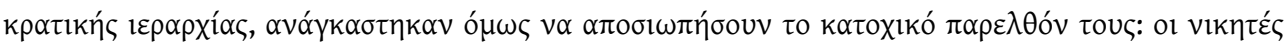

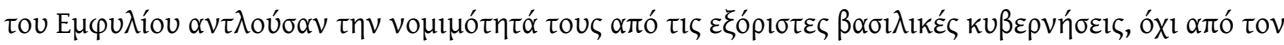

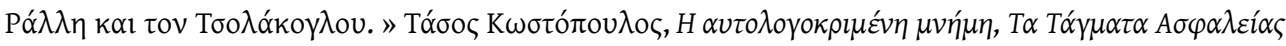

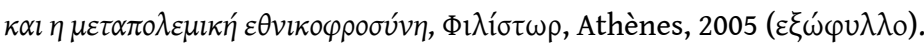

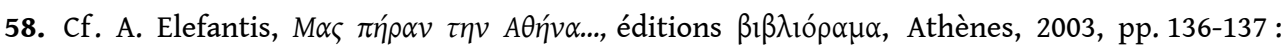

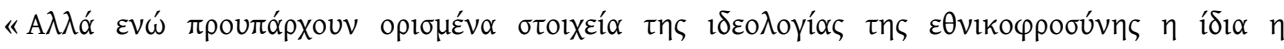

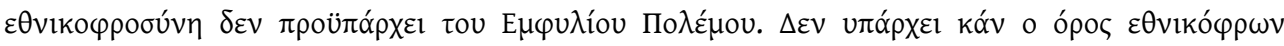

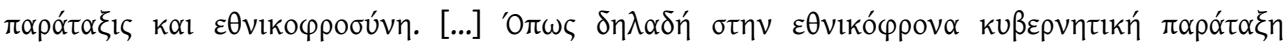

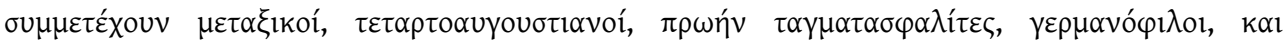

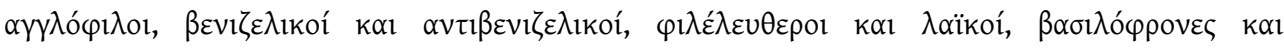

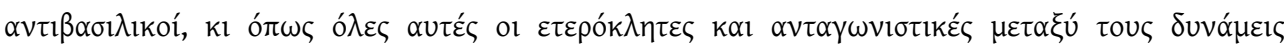

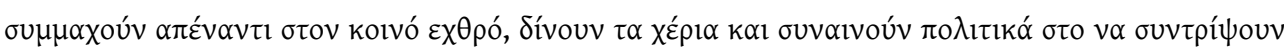

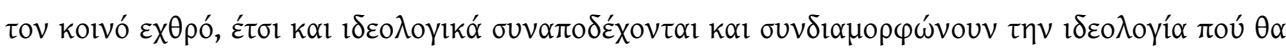

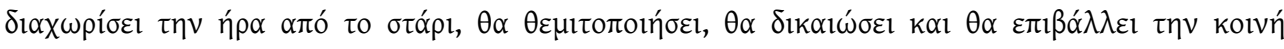

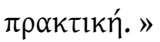

59. La réflexion et le discours des vainqueurs de la guerre civile se constituent donc sur le mode négatif avec l'anticommunisme d'État dans le rôle de dénominateur idéologique commun. Les classes dominantes peinent à articuler un discours cohérent et à se positionner sur le plan des

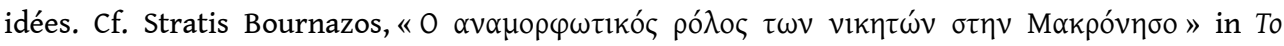

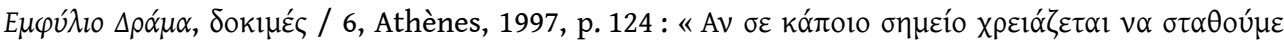

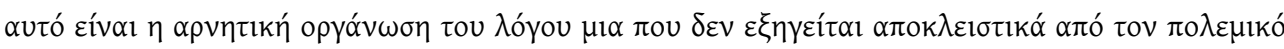

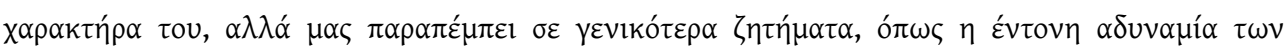

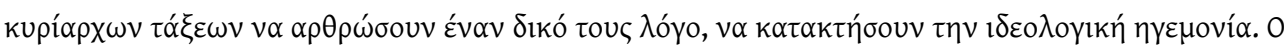

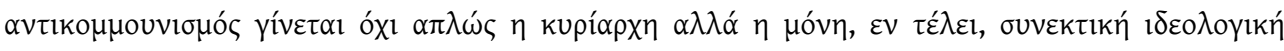
$\alpha \xi i ́ \alpha . »$

60. S'agissant de la guerre civile grecque, nous pouvons affirmer que la difficulté d'en parler commence déjà par le refus de la nommer ou d'en reconnaître l'existence. La guerre qui a opposé les forces de l'Armée Démocratique à celles de l'armée gouvernementale n'a été reconnue comme guerre civile qu'en 1981. Le foisonnement terminologique qui a été déployé jusque-là pour désigner ce conflit, illustre la difficulté pour les belligérants mais aussi pour la propagande des deux bords, d'assumer la réalité d'une guerre entre des gens vivant dans le même pays et par là même, le fantasme d' " une guerre fratricide ", impliquant à la fois le rejet de toute altérité et le déni de l'identité de l'adversaire. Au-delà de la réalité de la guerre civile, c'est le fantasme de ce conflit «fratricide " que cherchent à atteindre ou à travestir les discours de propagande. (Pour Nikos Sidéris, le refus de nommer les choses participe du déni de l'identité de l'Autre. Cf.

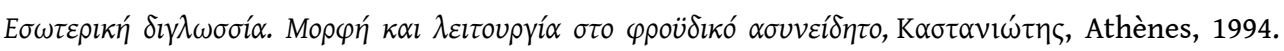
Quand le gouvernement grec traite les communistes de «Bulgares» et donc d'ennemis héréditaires, il procède au refus pur et simple du sens propre des mots.)

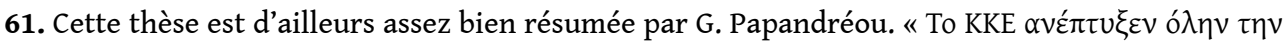

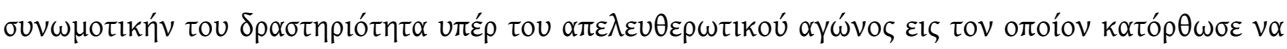

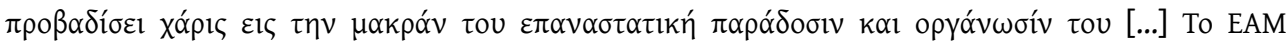

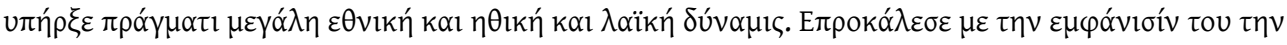

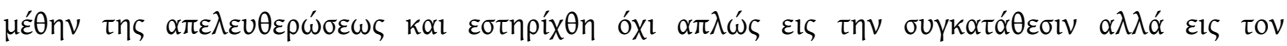

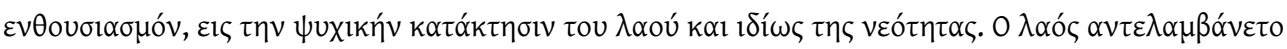

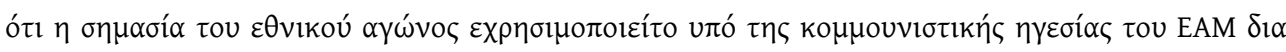

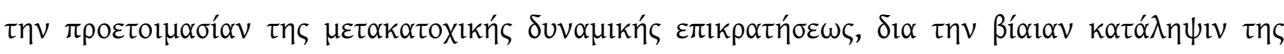

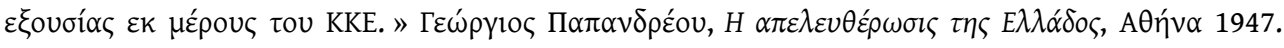

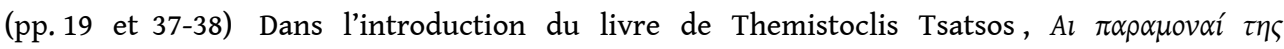

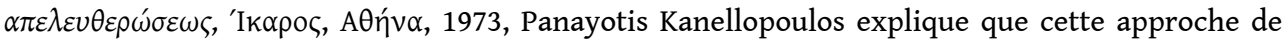




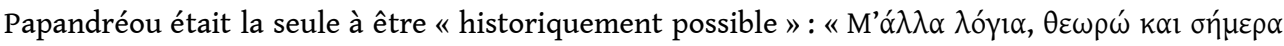

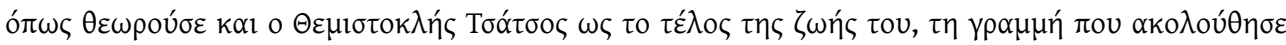

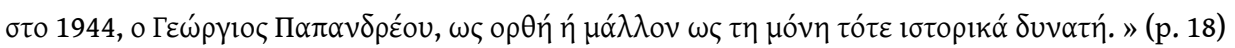

62. Les références aux héros de la guerre d'indépendance et aux figures des grands klephtes de la période ottomane faisaient partie d'un imaginaire populaire très partagé. Le discours libérateur de l'EAM s'en était également servi. Pour une présentation détaillée du mythe du klephte et de l'ambivalence de ses rapports avec le pouvoir et la rébellion, cf. Riki Van Boeschoten, From Armatolic to People's Rule. Investigations into the Collective Memory of Rrural Greece, 1750-1949, Editions

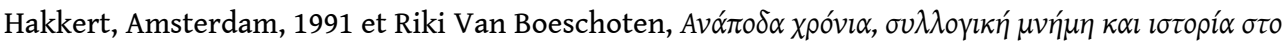

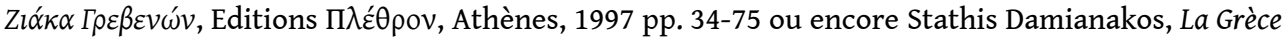
dissidente moderne, cultures rebelles, L'Harmattan, Paris, 2003.

63. Dans le discours rééducatif, il s'agit d'un terme nettement péjoratif et en aucun cas d'une reconnaissance implicite des détachements slavophones de l'Armée Démocratique, qui par ailleurs parlaient essentiellement le macédonien et pas le bulgare. Or, la Bulgarie représente à la fois l'ennemi de toujours et la force d'occupation de la dernière guerre. À ce titre, il est intéressant de consulter le rapport confidentiel de Dragoumis au ministre de l'Éducation nationale A. Papadimas où Dragoumis explique que des "raisons de politique extérieure " imposent l'emploi du terme «bulgare " à la place du terme "slavomacédonien » très répandu à l'époque pour désigner le macédonien, tout en affirmant qu'il faudrait y persister, même si cela n'était exact ni sur le plan linguistique ni au niveau des perceptions identitaires de cette

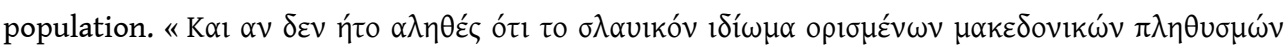

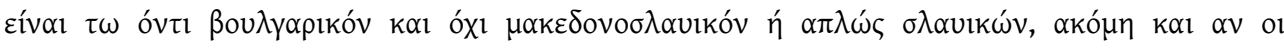

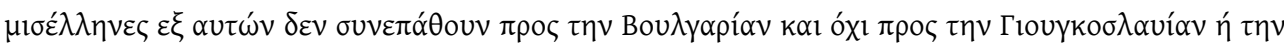

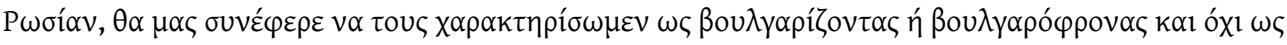

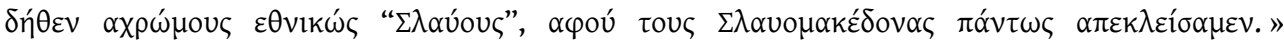
(pp. 9-10) Ү

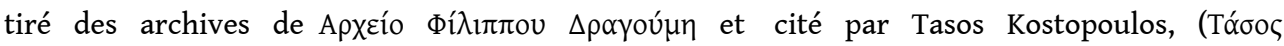

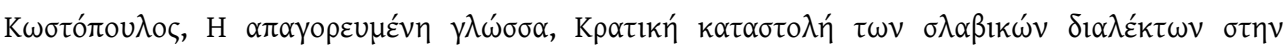

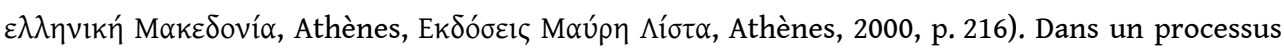
de diabolisation, la propagande grecque appelle globalement «bulgares » tous les communistes (parfois qualifiés de russes, quand ils ont une relation de parenté avec des communistes), tous les hommes de gauche et même tous ses opposants; elle appelle aussi de ce nom tous les "slavophones" de Grèce quelles que soient leur origine et leur langue. La Bulgarie, par son occupation d'une partie de la Grèce dans chacune des deux guerres mondiales, incarne l'ennemi slave par excellence et "'éam-o-bulgare » est donc un "traître ", "vendu à l'ennemi », son origine linguistique, ethnique ou géographique n'étant qu'accessoire. Cf. Vassilis K. Gounaris,

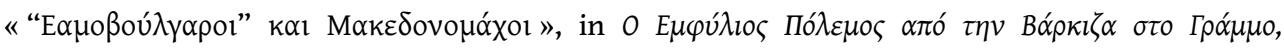

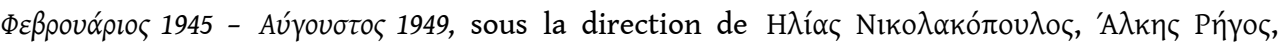

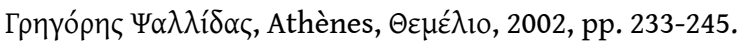

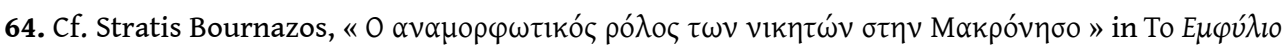

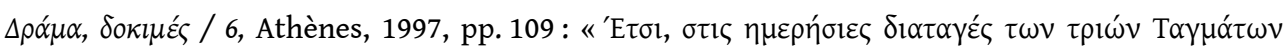

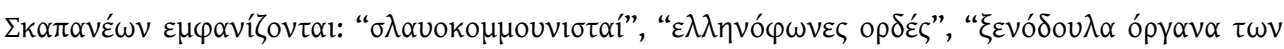

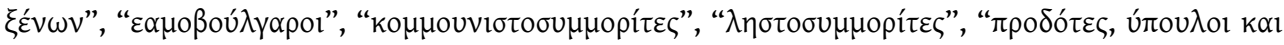

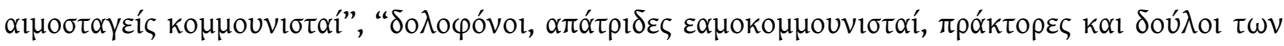

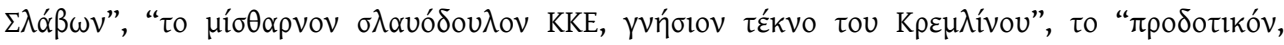

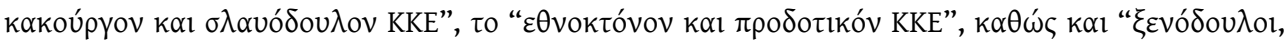

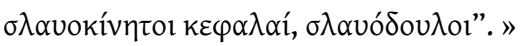

65. Cf. Nikos Sideris, « По

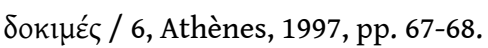


66. Le discours stéréotypé évoque plusieurs aspects de la novlangue de Georges Orwell, 1984, Paris Gallimard, 1950. Ainsi, en novlangue, un même mot comme «canelangue » peut avoir un sens laudatif s'il est appliqué à un membre du gouvernement ou péjoratif s'il est appliqué à un ennemi du gouvernement. Il devient donc impossible de l'utiliser pour dire du mal d'un membre du gouvernement. La population y est abreuvée de slogans comme : «la guerre, c'est la paix »; « la liberté, c'est l'esclavage », "l'ignorance, c'est la force » ou encore « $2+2=5$ » (à ce slogan, Winston réagit sur son journal en déclarant : «La liberté, c'est le pouvoir de dire que deux plus deux égalent quatre. ») Ce processus altère le « sens logique » des assujettis au régime. D'un autre côté, la novlangue est volontairement appauvrie pour rendre impossible l'expression et la formulation de pensées subversives. Dans 1984, bien qu'il soit toujours possible de dire que les décisions prises en haut lieu sont mauvaises, il sera impossible d'argumenter sur cela. De plus, les mots novlangues comportent peu de syllabes afin d'être prononcés plus rapidement et sont conçus pour être émis sans réflexion et afin d'anéantir l'affect et la connaissance intuitive des mots. Les fonctions symboliques ou métaphoriques du langage sont abolies.

67. La propagande officielle ne craint pas le ridicule et l'on demande aux détenus de construire des répliques du Parthénon et autres monuments historiques à fort coefficient national, de vénérer le roi et la reine des Grecs, dans des mises en scène dont personne n'est dupe, et de participer activement au salut de leur âme et à celui de leurs camarades en se transformant en " rééducateurs ».

68. Cette vision du passé n'est pas sans évoquer un autre cas d'école exploré par Ilya Platov in Cahiers Balkaniques, $\mathrm{n}^{\circ} 35$, dans son article «Barbare et infidèle : l'image de l'ennemi turc dans la guerre de 1876-1878 en Russie à travers la presse, les brochures de propagande, les correspondances et les mémoires. » Comme l'auteur l'explique (et l'analogie avec l'ennemi slave de la propagande grecque est saisissante), le Turc dans un certain imaginaire russe est assimilé à l'ennemi musulman de toujours : «Les historiens russes, de N. Karamzin à S. Soloviev, avaient répandu l'idée selon laquelle la lutte contre les nomades islamisés constituait un chapitre déterminant dans le drame qui conduirait la nation russe à prendre conscience d'elle-même. Selon ce schéma, la lutte des Slaves orthodoxes pour l'indépendance représente le dernier chapitre d'une grande lutte qui s'est étalée sur plusieurs siècles. Son inscription dans un ordre de représentations très largement partagé confère à cette représentation une intelligibilité qui dépasse largement le cadre d'un public instruit. Le discours historiographique et savant rejoint ainsi les croyances populaires. Dans un discours prononcé en 1876, Ivan Aksakov s'interroge sur les raisons de la popularité de la guerre contre les Turcs au sein des masses populaires. Le souvenir de la conquête mongole lui fournit une clef d'explication : « La lutte contre l'infidèle, le Tatare, est un motif récurrent dans l'histoire du peuple russe [...] elle évoque les souffrances endurées, immortalisées dans les chants populaires et les récitations. Au cours des fêtes religieuses [...] Ce ne sont pas les faits historiques en tant que tels, mais l'ennemi lui-même, le mal lui-même qui paraissent familiers. Il n'y a pas d'ennemi plus populaire que le Turc ». (Cf. I. S. Aksakov, “Reč' vice-prezidenta Moskovskogo slavjanskogo blagotvoritel'nogo komiteta v zasedanii 24 oktjabrja 1876 goda", Pravoslavnoe obozrenie, décembre 1876, $\mathrm{n}^{\circ} 12$, pp. 833-834.)

69. Il suffit de songer à la position de l'Église à propos du camp de rééducation de Makronissos. Ce lieu de déportation et de torture, où des milliers de jeunes recrues et des civils ont été suppliciés, a été comparé par l'église officielle au "réservoir de Siloé », lieu de salut spirituel pour des " pécheurs » en repentance. Même si l'Église grecque n'a pas de pouvoir comparable à celui de l'église catholique pendant la guerre civile espagnole, force est de constater qu'en Grèce comme en Espagne, les dirigeants se placent massivement du côté des forces royalistes. Et le ministère de la Justice est le premier à reconnaître l'importance du discours ecclésiastique, à la fois comme moyen de pression supplémentaire en vue de l'obtention d'une déclaration de repentir et comme caution morale face aux protestations de l'opinion publique et des

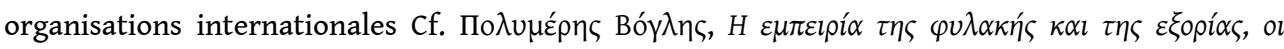




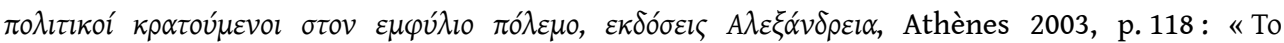

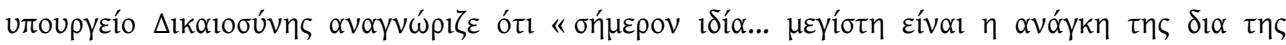

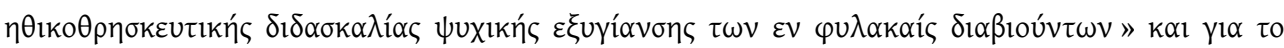

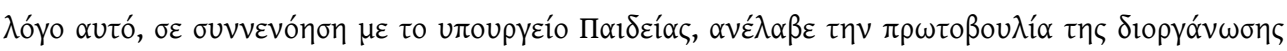

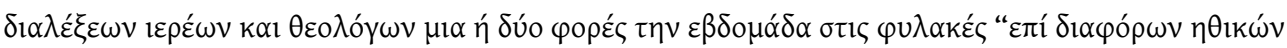

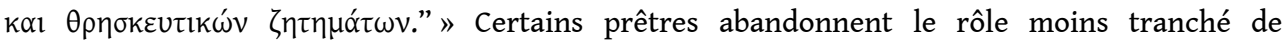
conseiller spirituel ou de directeur de conscience pour endosser celui de Grand Inquisiteur. Le cas de Stylianos Kornaros, archevêque en poste à Makronissos en est l'exemple type. Il dénonce systématiquement ceux qui lui donnent des informations sous le secret de la confession et assiste

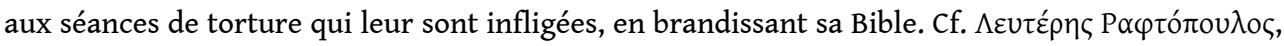

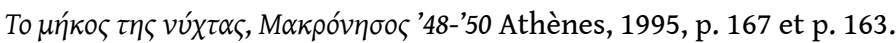

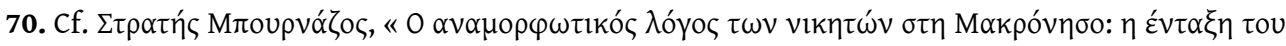

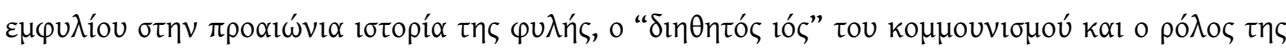

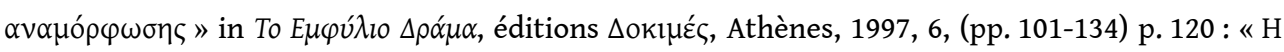

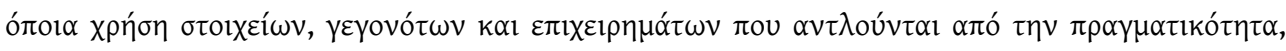

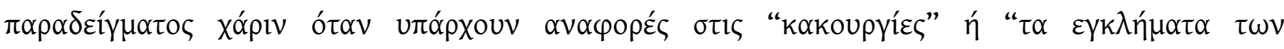

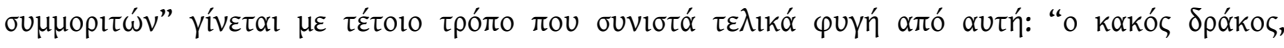

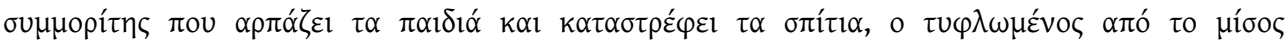
какоúpүоч." "

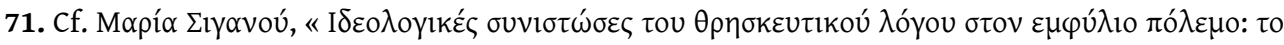

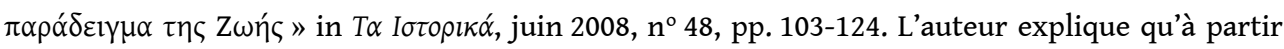
de 1947, le discours de Zoi change et passe d'une critique de l'idéologie communiste qui allait de pair avec une critique de l'héritage individualiste des Lumières, à une injonction d'extermination physique des communistes, considérés comme des ennemis absolus.

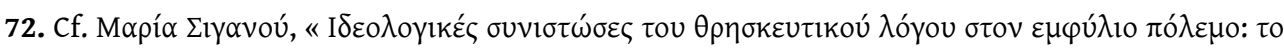

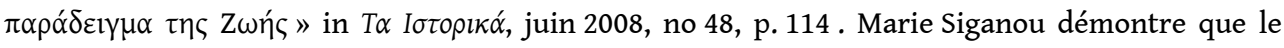
communisme se trouve rejeté au-delà du champ de la normalité puisqu'il n'est plus représenté comme un danger national ou social mais comme un obstacle à la volonté divine. Il acquiert alors les traits du Mal absolu et se transforme d' "ennemi de la Nation », en "force des ténèbres ", « antéchrist » ou encore « monstre communiste. »

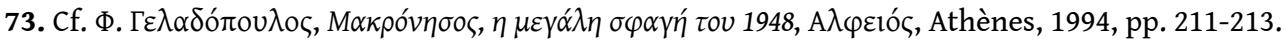
L'exemple de Katsimihas, ancien résistant transformé en rééducateur à Makronissos en dit long

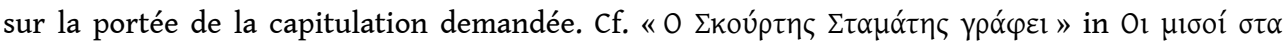

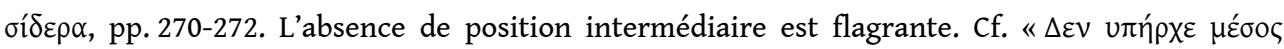

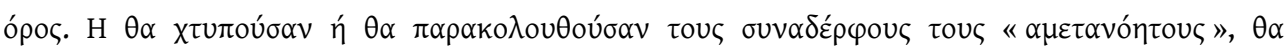

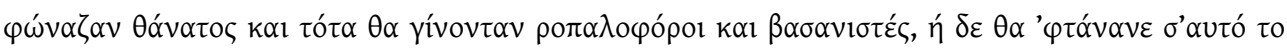

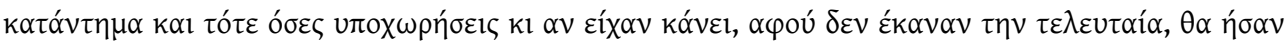

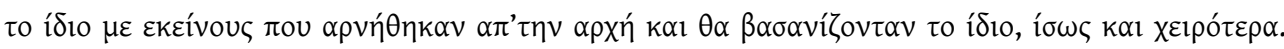

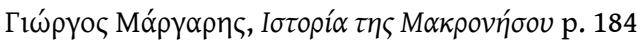

74. La condamnation des signataires de la déclaration de repentir par le PC est en partie liée aux conséquences de la déclaration de repentir sous la dictature de Métaxas quant la police de

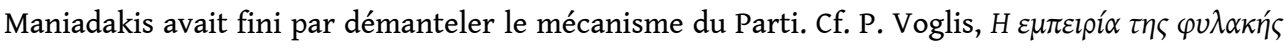

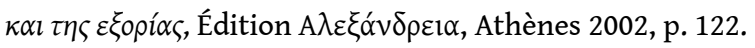

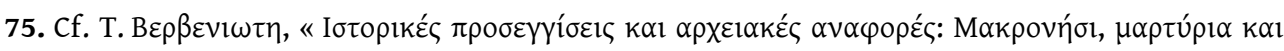

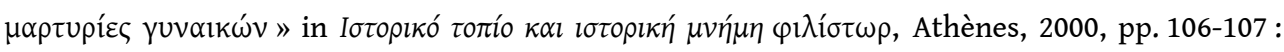
L'auteur prend comme hypothèse de travail la présence d'un idéal d'honneur qui rattache l'individu à la collectivité, très fort dans le monde rural en général et donc dans la société

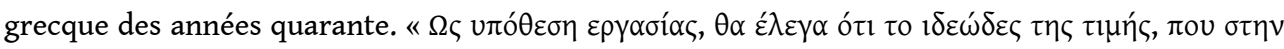

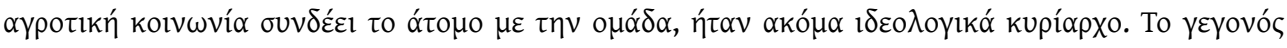




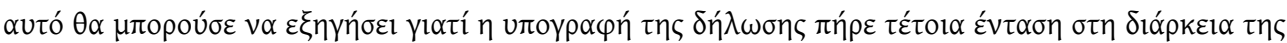

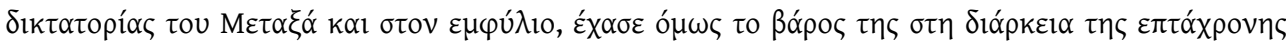

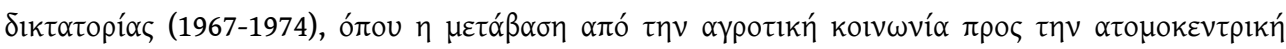

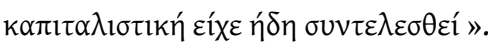

76. Cf. J. Dalègre, La Grèce de 1940 à nos jours, L'Harmattan, Paris, 2006, p. 117.

77. Joëlle Dalègre évoque très justement le climat d'exclusion qui persiste bien longtemps après la fin de la guerre civile : « Même si en février 1950, la loi martiale est levée, si les condamnés à mort pour fait de guerre civile ne sont plus exécutés et si les peines de prison sont peu à peu réduites, la législation d'exception élaborée à partir de 1936 reste en vigueur. La déportation administrative sur décision préfectorale, renouvelable chaque année, sévit ; l'île de Makronissos ne ferme son camp de rééducation qu'en 1954, l'île d'Aghios Efstratios reçoit des déportés jusqu'en 1963 et, lorsque G. Papandréou ferme ces camps en 1964, il reste encore 1400 personnes assignées en diverses îles pour ne avoir montré de signe de reconversion idéologique. ", Joëlle Dalègre, La Grèce de 1940 à nos jours, L'Harmattan, Paris, 2006, pp. 116-117.

78. Cf. Athéna Skoulariki, « La Crise Macédonienne (1991-1995) et la question des slavophones en Grèce. » Balkanologie VII [1], juin 2003, pp. 147-156. (p. 150)

79. L'historiographie officielle depuis la fin de la guerre civile jusqu'à la chute de la dictature des colonels s'est construite en relation étroite avec la mémoire des vainqueurs. Un rapport de subordination des pratiques historiographiques, édificatrices de mémoire collective, au discours étatique persiste très clairement sur toute cette période, à l'exception peut-être du cours «printemps » des années soixante, précédé en 1958 par la victoire électorale du parti de gauche $\mathrm{E} \Delta \mathrm{A}$. L'étude des manuels scolaires proposés aux élèves pendant toute cette période nous

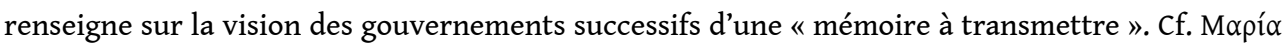

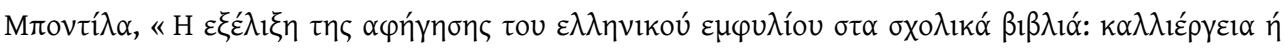

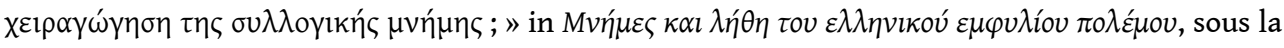
direction de Riki Van Boeschoten, Tasoula Vervenioti, Eutychia Voutyra, Vassilis Dalkavoukis et

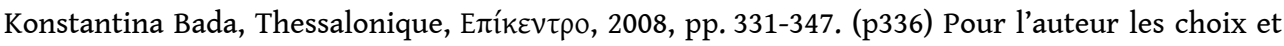
les priorités de chaque gouvernement se retrouvent systématiquement dans les manuels

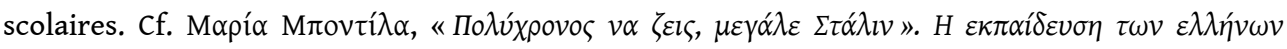

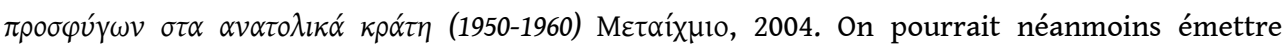
quelques réserves quant à la véracité générale de cette affirmation, qui nous semble difficile à établir quand plusieurs manuels scolaires coexistent. Il est vrai qu'en Grèce jusqu'à très récemment, il n'y avait qu'un seul manuel d'histoire agréé par le Ministère.

Entre 1949 et 1967, la guerre civile ne fait pas partie du programme enseigné à l'école. Pourtant, le discours anticommuniste est abondant. L'idéologie d'extrême droite est enseignée à l'armée, aux écoles d'officiers ou à la police, elle est omniprésente dans la presse et les discours politiques, elle pèse sur la vie culturelle du pays. À l'école, cette idéologie est véhiculée par les cours de littérature, les cours d'histoire ancienne qui s'efforcent de montrer « la grandeur et la continuité

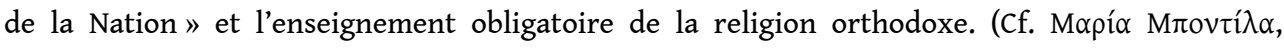

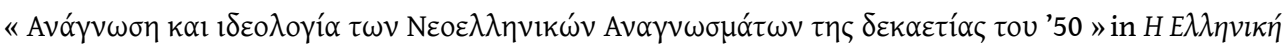

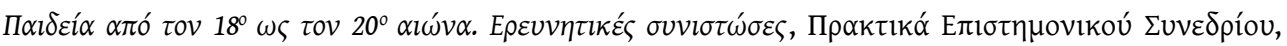
Florina, 2005. En ce qui concerne la vision nationaliste de l'enseignement de l'histoire grecque de l'Antiquité, Cf. «La grandeur des ancêtres à travers les manuels scolaires de 1950 à nos jours » (pp. 23-44) in Mélanges offerts à Astérios Argyriou, sous la direction de Astérios Argyriou et Irini Tsamadou-Jacoberger, Paris, L'Harmattan, 2000). Elle est très présente dans les cours de catéchisme et les activités éducatives extrascolaires organisées par des associations ultraorthodoxes et nationalistes. Elle influe sur le choix de la langue des enseignements, qui est une langue savante et puriste, peu accessible à l'élève moyen. Bref, le discours anticommuniste est omniprésent et cherche à former la jeunesse dans ses idéaux mais l'histoire de la guerre civile 
n'est pas officiellement racontée. Dans ce sens, il y a continuité entre le déni officiel de l'existence d'une guerre civile et le silence des manuels d'histoire d'un côté et le triomphe de la mémoire des vainqueurs et la surreprésentation de l'idéologie de la loyauté nationale de l'autre. Pour Maria Bodila, le terrorisme d'État fait partie de la vie quotidienne si bien que l'absence de référence à la guerre civile dans les manuels scolaires ne fait que contraster avec les conséquences concrètes du conflit, tout ce dont ces élèves sont les témoins directs. Il s'agit de

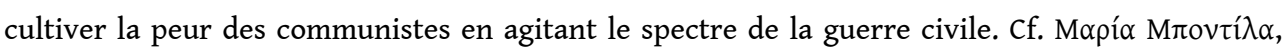

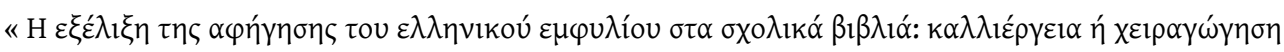

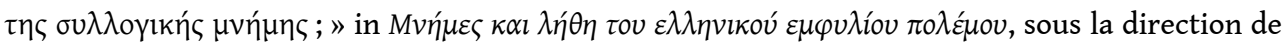
Riki Van Boeschoten, Tasoula Vervenioti, Eutychia Voutyra, Vassilis Dalkavoukis et Konstantina

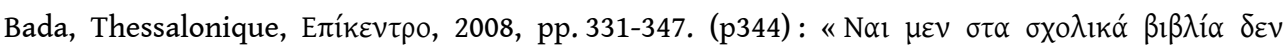

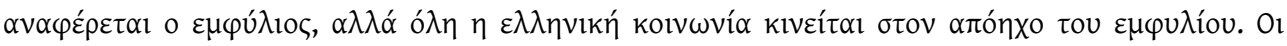

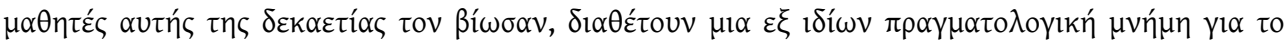

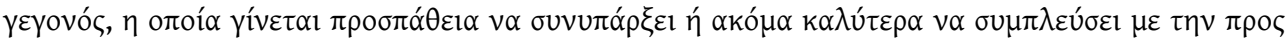

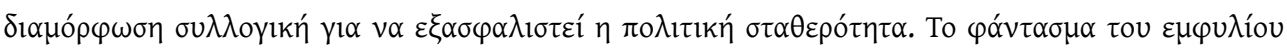

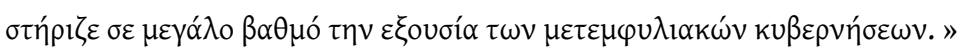

Les manuels scolaires de la période de la dictature à la fin des années 60 se différencient de ceux de la période précédente par l'abandon formel de cette posture historiographique qui refuse de traiter un passé jugé beaucoup trop récent. Le manuel d'histoire de Matarasi-Papastamatiou et l'ouvrage de propagande de Dafni, enseigné en complément du manuel de MatarasiPapastamatiou, utilisent les références à la guerre civile et au danger communiste pour légitimer et conforter le régime. La période étudiée s'étend ainsi jusqu'au coup d'État de 1967, qui est naturellement présenté comme l'ultime recours contre une menace de guerre civile fantasmée et fantomatique. Il s'agit de reconstruire la mémoire collective et d'entraîner une série d'identifications chez un public qui n'a pas de souvenirs personnels ou d'expérience propre de la guerre civile, puisque dix-huit ans se sont écoulés depuis la fin du conflit. L'objectif des historiens qui ont rédigé ces ouvrages est de passer de l'anticommunisme ordinaire à la prise de position en faveur des décisions politiques de la junte militaire. (Il s'agit de la formulation habituelle sur

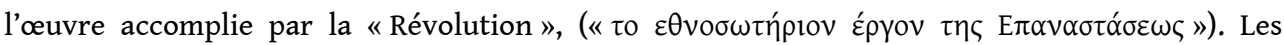
rédacteurs des deux ouvrages feront partie des intellectuels engagés en faveur de la junte. Cf.

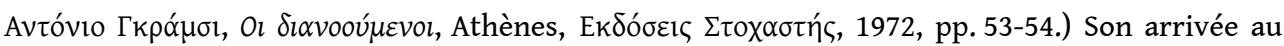
pouvoir est jugée salutaire pour la Nation et l'EAM est encore présenté comme une force antinationale qui aurait dupé de vrais patriotes pour tenter d'installer au pouvoir un régime

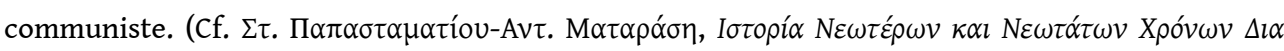

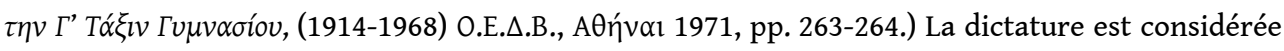
comme " une nécessité historique », tout comme l'assujettissement du pays aux États-Unis et au

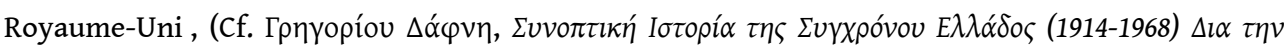

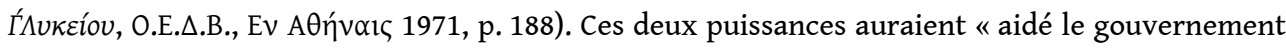

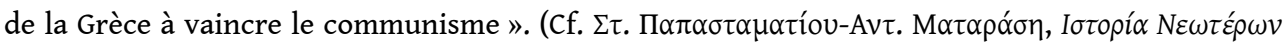

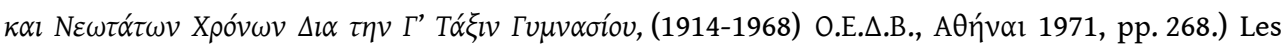
manuels scolaires de la période de la junte, poussent à l'extrême, l'idéologie de la loyauté nationale, que la guerre civile a léguée et ce faisant la discréditent à tout jamais.

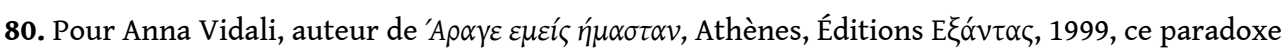
s'est exprimé par l'absence de toute référence à la question dans les manuels scolaires ou le discours historiographique officiel et en même temps par des conséquences quotidiennes qu'elle qualifie de traumatisantes pour les citoyens du pays dans les années 50 et 60 et par la difficulté d'en parler même après la fin de la dictature et la légalisation du PC grec au milieu des années

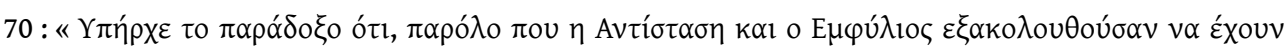

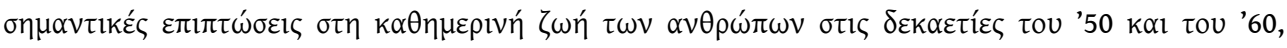




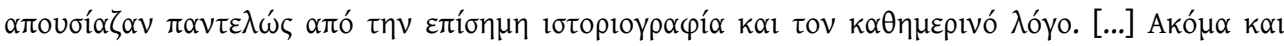

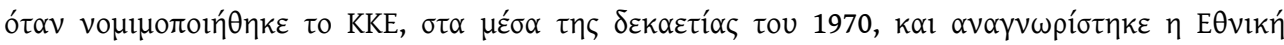

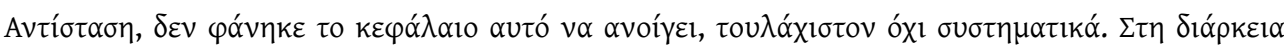

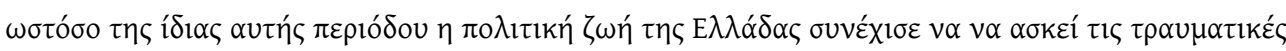

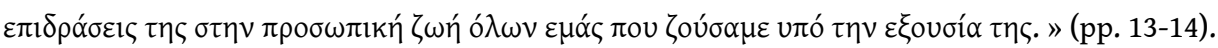

81. Un devoir d'oubli décrété sous forme d'autodafé symbolique et voté par l'ensemble des partis politiques qui ont décidé de faire brûler des documents historiques de première importance. Les fiches techniques de la police constamment réactualisées, qui répertoriaient déjà sous Métaxas ceux qui étaient soupçonnés d'avoir des convictions subversives, ont fini par être détruites (Cf. Joëlle Dalègre, La Grèce depuis 1940, Paris, L'Harmattan, 2006, p. 180 : «En 1991, enfin, au grand dam des historiens, les 16 millions de dossiers personnels, amassés par les services de renseignements depuis près de trois générations sont détruits, éliminant tout retour possible au passé. [...] Tout cela ne va pas sans nouvelles tragédies. Comment prouver, 40 ans plus tard, une appartenance à la résistance que l'on avait tout fait pour oublier ou faire oublier ? On voit de faux résistants reconnus, de vrais héros oubliés. »)

82. Comme le démontrent les travaux de Graham Dawson sur la mémoire de la guerre civile en Irlande du Nord, le manque de reconnaissance des traumatismes des deux bords conduit à une politique de la souffrance (politics of suffering) et à une polarisation de la transmission mémorielle qui entrave toute perspective de réconciliation réelle entre les acteurs. Cf. Graham Dawson, “Trauma, Memory, Politics" in Kim Lacy Rogers, Selma Leydesdorff \& Graham Dawson, (eds.), Trauma and Life Stories. International Perspectives, London \& New York, Routledge Studies in Memory and Narrative, 1999.

83. Le besoin de réparation est à entendre ici dans le sens éthique du terme et toujours dans la cathartique de la parole libérée. Paul Ricœur estime de son côté que l'amnistie ne se résume pas en une amnésie, mais s'exprime à travers le pardon en tant que reconnaissance préalable de la culpabilité de l'agresseur et travail sur la mémoire collective. Son approche, à notre sens plus subtile, se différencie de la sorte de celle de Summerfield D. in "Raising the dead. War reparation and the politics of memory", British Medical Journal, où l'auteur évoque les ravages de l'impunité pour les crimes de guerre et le besoin d'une réparation matérielle et / ou morale, pour les victimes, mais minimise la portée thérapeutique de la verbalisation.

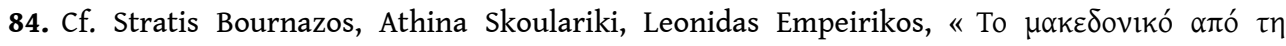

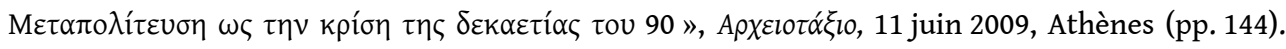
Sur le refus du retour et de l'accord de la nationalité grecque aux réfugiés politiques

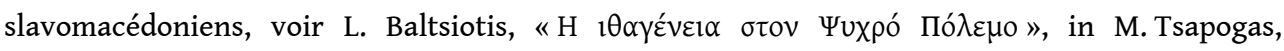

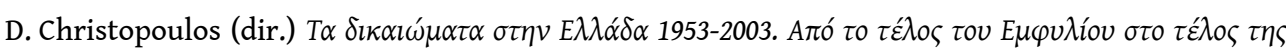

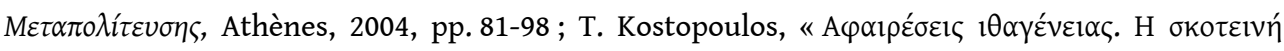

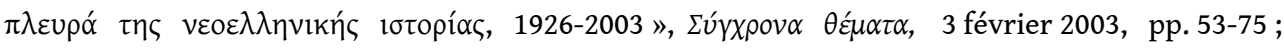
D. Christopoulos, "Péripéties de la nationalité hellénique », in Anne Sophie Lamblin-Gourdin (dir.) Un droit pour des hommes libres, Études en l'honneur d'Alain Fenet, Amiens, Litec, 2008. Sur les

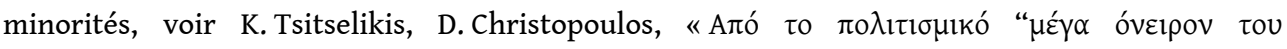

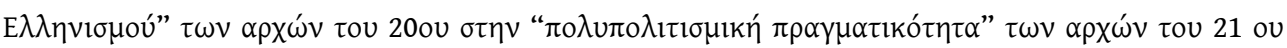

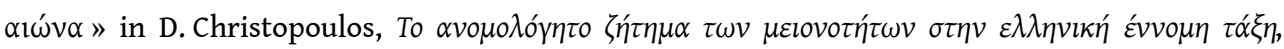
Athènes, Kрıєıкท́, KEMO, 2008, pp. 33-67. 


\section{RÉSUMÉS}

Le traitement de la question macédonienne durant la guerre civile grecque interroge la mémoire du conflit entre oubli, déni et instrumentalisation politique. Le Parti communiste grec essaya de concilier la politique nationale avec la géopolitique internationale, en tenant compte des revendications macédoniennes et de la stratégie de Tito. L'engagement des Macédoniens slavophones de Grèce à la résistance communiste et à la guerre civile exprima une lutte identitaire et sociale. La propagande gouvernementale transforma la question macédonienne en « preuve suprême » d'une trahison nationale » des communistes devant « le danger slave » et occulta le collaborationnisme dont les milices nationalistes se rendirent coupables. Malgré la démocratisation du pays et le travail de l'historiographie contemporaine, le traitement actuel de la question dans les discours politiques et journalistiques montre la vivacité du nationalisme d'antan au sein de la société civile.

Treating the Macedonian question during Greek civil war means dealing with the memory of the conflict, somewhere between oblivion, denial and political instrumentation. The Greek

Communist Party tried to reconcile national politics with international geopolitics in its consideration of the Macedonian demands and Tito's strategy. On the other hand the engagement of slavophone Macedonians of Greece, in the communist resistance and the civil war, expressed a social struggle and an identity conflict. The governmental propaganda transformed the Macedonian question into the "ultimate proof" of the communists committing "national treason" with regard to the "Slavic danger" and did its best to hide the collaborationism, of which, the nationalist militia was guilty of. Despite the return of Democracy

in the country, the way the question is actually being treated in politics and by the media is revelatory of the nationalism reigning in the past and still evident even amidst the civil society of the present age.

\section{INDEX}

motsclesmk ЈУГОСЛАВИЈА, БАЛКАНОТ, ГРЦИЈА, ЛЕРИН, МАКЕДОНИЈА, СКОПЈЕ

Mots-clés : Slavomacédoniens, Bataillons de sécurité, parti communiste grec, AFG, SNOF, Armée démocratique, EAM, NOF, Zachariadis Nikos (1903-1973), MAY, NOF, NOMC, Ohrana, SNOF, Terreur Blanche, Tzimas Andréas (1909-1972), VMRO-DPMNE, Metaxás Ioannis (1871-1941) motsclestr Balkanlar, Yunanistan, Makedonya, Yugoslavya, Florina, Varkiza, Üsküb, Yunan İç Savaşı (1946-1949)

Thèmes : Histoire

Index chronologique : guerre civile grecque (1946-1949)

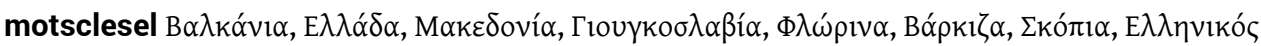

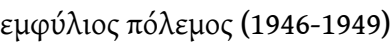

Keywords : Macedonia, Greek civil war (1946-1949), Slavomacedonian, greek communist party, SNOF, NOF, Zachariadis Nikos (1903-1973), Balkans, Greece, Yugoslavia, Florina, Varkiza, Skopje

Index géographique : Macédoine, Balkans, Grèce, Yougoslavie, Varkiza, Skopje, Florina 